\title{
Multiple Input Single Output (MISO) Tablet/ Phone Charger
}

\author{
A Thesis \\ Submitted to \\ The Faculty of California Polytechnic State University, \\ San Luis Obispo \\ In Partial Fulfillment \\ of the Requirements for the Degree of \\ Master of Science in Electrical Engineering
}

By

Kevin Paul Wong 
(C) March 2013

Kevin Paul Wong

ALL RIGHTS RESERVED 


\section{Committee Membership}

TITLE:

AUTHOR:

DATE SUBMITTED:

COMMITTEE CHAIR:

COMMITTEE MEMBER:

COMMITTEE MEMBER:
Multiple Input Single Output (MISO)

Tablet/ Phone Charger

Kevin Paul Wong

April 2013

Dr. Taufik, Professor

Electrical Engineering Department

California Polytechnic State University, San Luis Obispo

Dr. Dennis Derickson, Department Chair Electrical Engineering Department California Polytechnic State University, San Luis Obispo

Dr. Tina Smilkstein, Assistant Professor Electrical Engineering Department California Polytechnic State University, San Luis Obispo 


\begin{abstract}
Multiple Input Single Output (MISO) Tablet/ Phone Charger

Author: Kevin Paul Wong
\end{abstract}

This thesis entails the design and implementation of a multiple input single output (MISO) DC-DC converter using the flyback topology to charge tablets/ smartphones or any USB powered portable device. The MISO converter will enable the use of various renewable energy sources such as a solar panel/ rechargeable battery combination, bicycle dynamo, hydroelectric power, and wind turbine. This paper will cover the design, simulations, and test results of the MISO converter. The flyback topology was chosen due to its low part count and its efficiency at low power. The proposed converter has a nominal $12 \mathrm{~V}$ input to output USB 2.0 requirements $(5 \mathrm{~V}$ at $2.5 \mathrm{~W})$. Results from both computer simulation using LTSpice and hardware tests demonstrate the functionality of the proposed MISO converter with solar/battery and bicycle dynamo inputs. Overall performance of the converter in terms of efficiency, line and load regulations, as well as its charging ability to a cell phone will be presented in this report.

Keywords: Flyback, Converter, Renewable, Tablet, Phone, Charger, MIC, MISO 


\section{Acknowledgements}

I would like to take this time to thank my parents for providing me the opportunity as well as supporting me though out my Bachelor's and Master's Degree in Electrical Engineering at Cal Poly. Also, I would like to thank the engineers at Linear Technology, my friends, and fellow classmates, especially Jeovany Vega and Allan Agatep, who have always had my back throughout my college career, supporting and encouraging me to push through and do my best. Finally, I would like to thank my advisor, Dr. Taufik, for being patience, kind, and an exceptional mentor. Whose teaching style inspired me to constantly learn and stick on the path of an Electrical Engineer. 


\section{Contents}

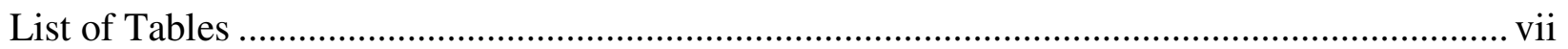

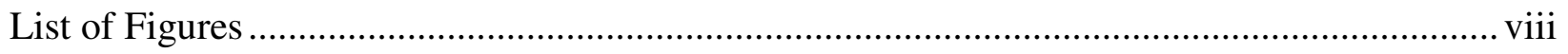

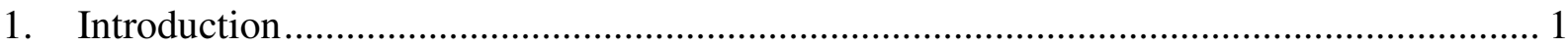

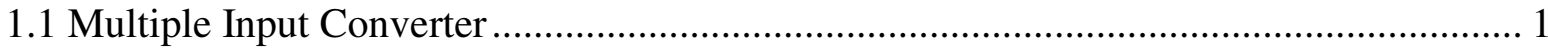

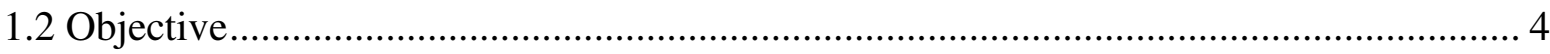

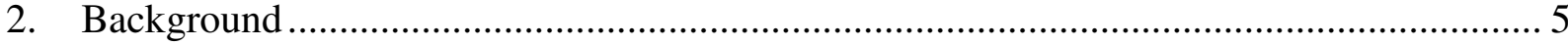

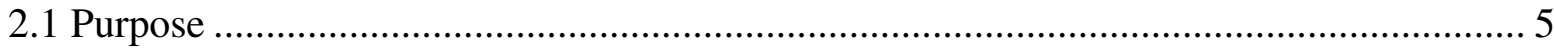

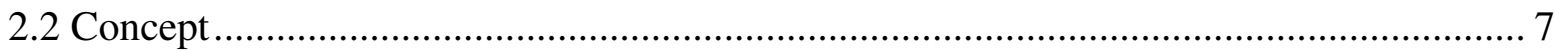

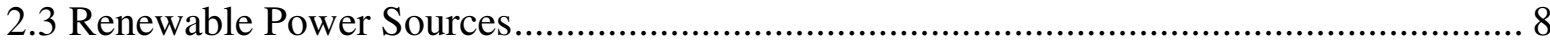

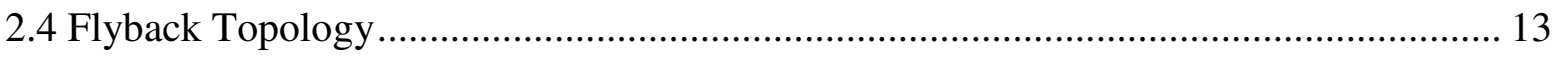

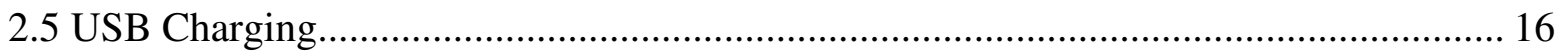

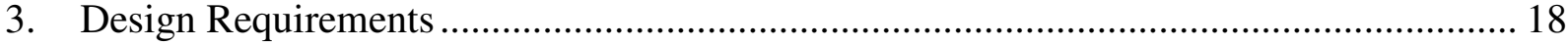

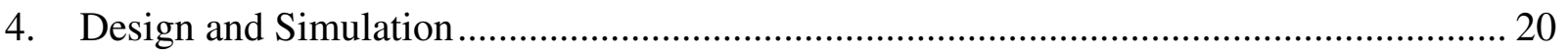

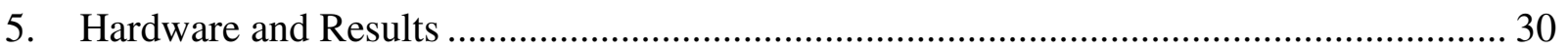

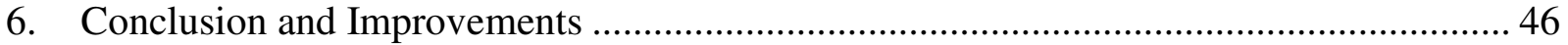

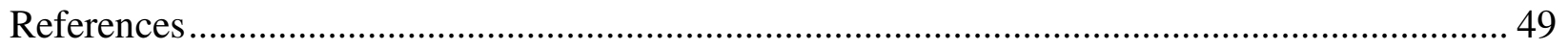

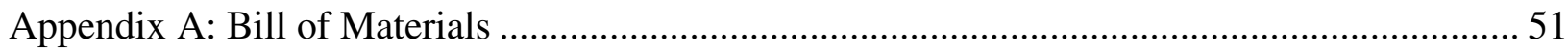

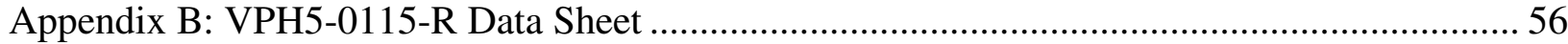

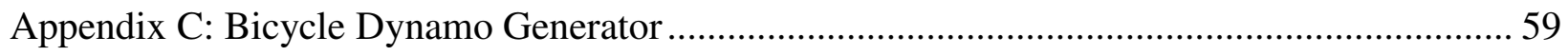

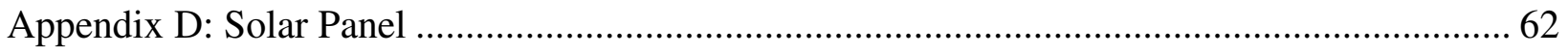




\section{List of Tables}

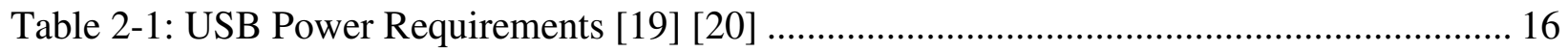

Table 2-2: Load Device Requirements Using a Standard Downstream Port [19]..................... 16

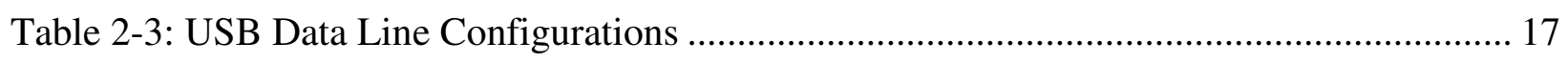

Table 3-1: Summary of Design Requirements of MISO Converter ....................................... 19

Table 5-1: Efficiency and Load Regulation with One Source ............................................. 41

Table 5-2: Efficiency and Load Regulation with Two Sources............................................ 41

Table 5-3: Performance at Max Load with Two Sources ......................................................... 44 


\section{List of Figures}

Figure 1-1: Multiple Input Single Output Transformer Diagram ............................................. 2

Figure 2-1: Overall System Block Diagram .................................................................... 7

Figure 2-2: Etap, Solar Panel Diagram [9] ........................................................................ 8

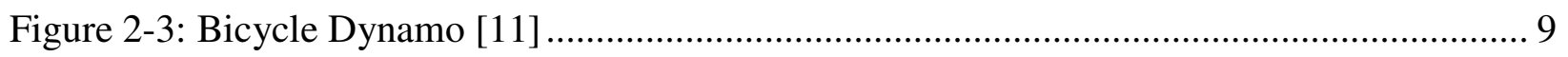

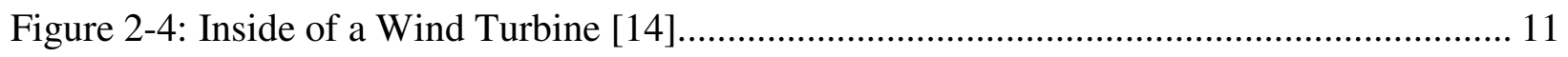

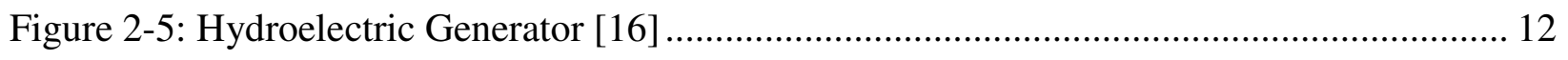

Figure 2-6: Comparison between CCM, DCM, and TM for a Flyback Power Supply [17] ........ 14

Figure 2-7: Two States of a Flyback Converter (When the Switch is Closed (ON) and When

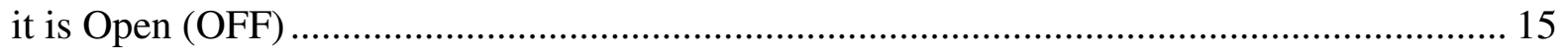

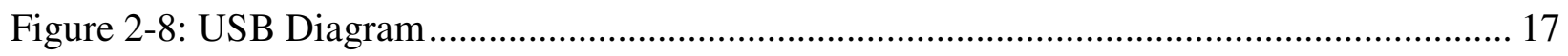

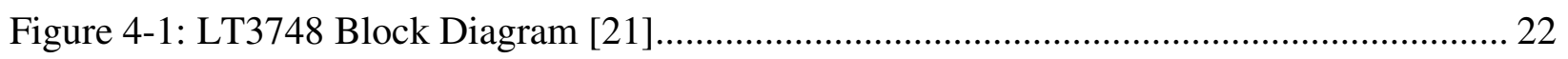

Figure 4-2: MISO Flyback Converter Schematic ............................................................ 27

Figure 4-3: Regulated 5V Output with 500mA Load ...................................................... 28

Figure 4-4: MISO Converter Secondary Winding Current and Switching Node....................... 28

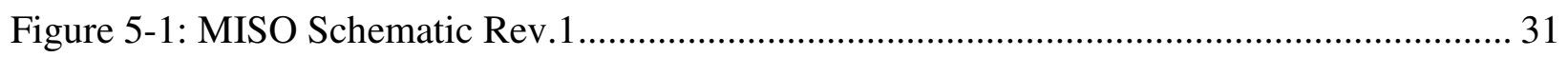

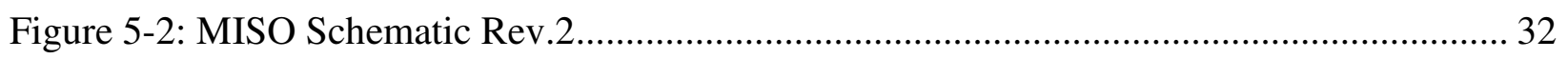

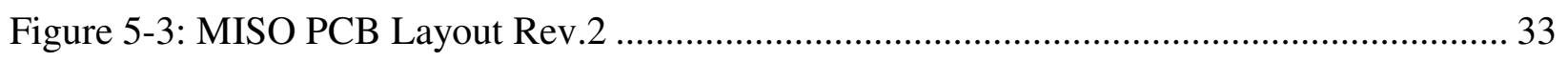

Figure 5-4: MISO PCB Layout Rev.2 Modified ................................................................ 34

Figure 5-5: Multiple Input Single Output (MISO) Converter .............................................. 35

Figure 5-6: MISO Test Setup Block Diagram ................................................................. 36

Figure 5-7: MISO Test Setup at Full Load with Two Inputs.............................................. 36

Figure 5-8: Solar Panel Test Setup Block Diagram.............................................................. 37

Figure 5-9: Solar Panel and Bicycle Dynamo Test Setup Block Diagram ............................... 37

Figure 5-10: Solar Panel Charge Testing (Drawing 74.5mA) .............................................. 38

Figure 5-11: Solar Panel and Bicycle Dynamo Charge Testing (Solar Drawing 27.5mA,

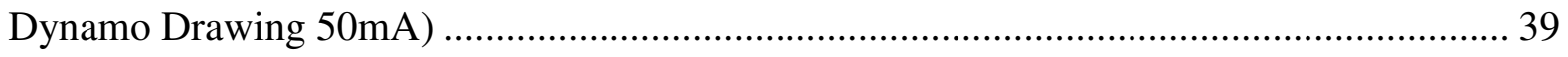

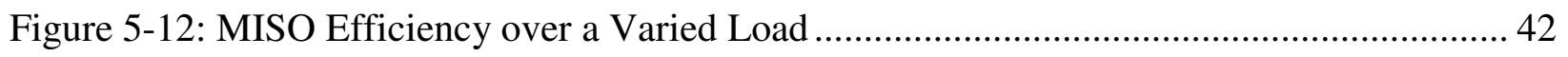

Figure 5-13: Pout Max under Multiple Source Conditions .................................................... 43

Figure 5-14: Output Peak-to-Peak Ripple at Full load with Two Sources ............................... 43 


\section{Introduction}

\subsection{Multiple Input Converter}

In the past few decades advancements in renewable energy and power electronics has improved greatly. With higher efficient converters, solar panels, wind turbines, etc. many applications for renewable energy have arisen. Most of these renewable energy converters are single-input single-output or single-input multiple-output depending on the requirements of the application. If it weren't limited to using only one type of renewable energy source it would become easier to obtain power whenever and wherever we want. Once a renewable energy source disappears, like when the sun sets, solar panels become useless and unusable. Therefore, using multiple types of renewable energy sources to power an application becomes highly desirable. Recently in the past few decades more studies on multiple-input converters (MIC) have been done in order to combine multiple power sources.

With a MIC the challenge is trying to find a reliable way to combine the various sources. There are a couple of obvious ways to do this; combine the sources in series or in parallel, however, problems arise when using these topologies. When placing the sources in series the MIC can obtain a regulated output, but if a source was to short the variation in the input voltage would be too great to maintain the regulated output or even worse if a source was to be removed completely the MIC would not be a complete circuit and stop functioning. Same goes with sources in parallel, if a source was to short/ fault all the other sources would then be shorted as well and the MIC would stop working. However, if the source was removed instead the other sources would be fine, but the MIC would not be able to deliver as much power as before, 
therefore protection is needed. A more promising concept is to combine the energy from the inputs and store/ combine them in a transformer creating a convenient way to combine energy and provide isolation between sources and the output [1]. This is accomplished thanks to Magnetomotive force (MMF). Amperes law states that the MMF around a closed loop path $\left(1_{c}\right)$ inside the transformer core is equal to the product of the number of turns and current. The MMF generated by each input can be determined when the other sources are off, therefore by using superposition the resulting linear MMF can be added up.

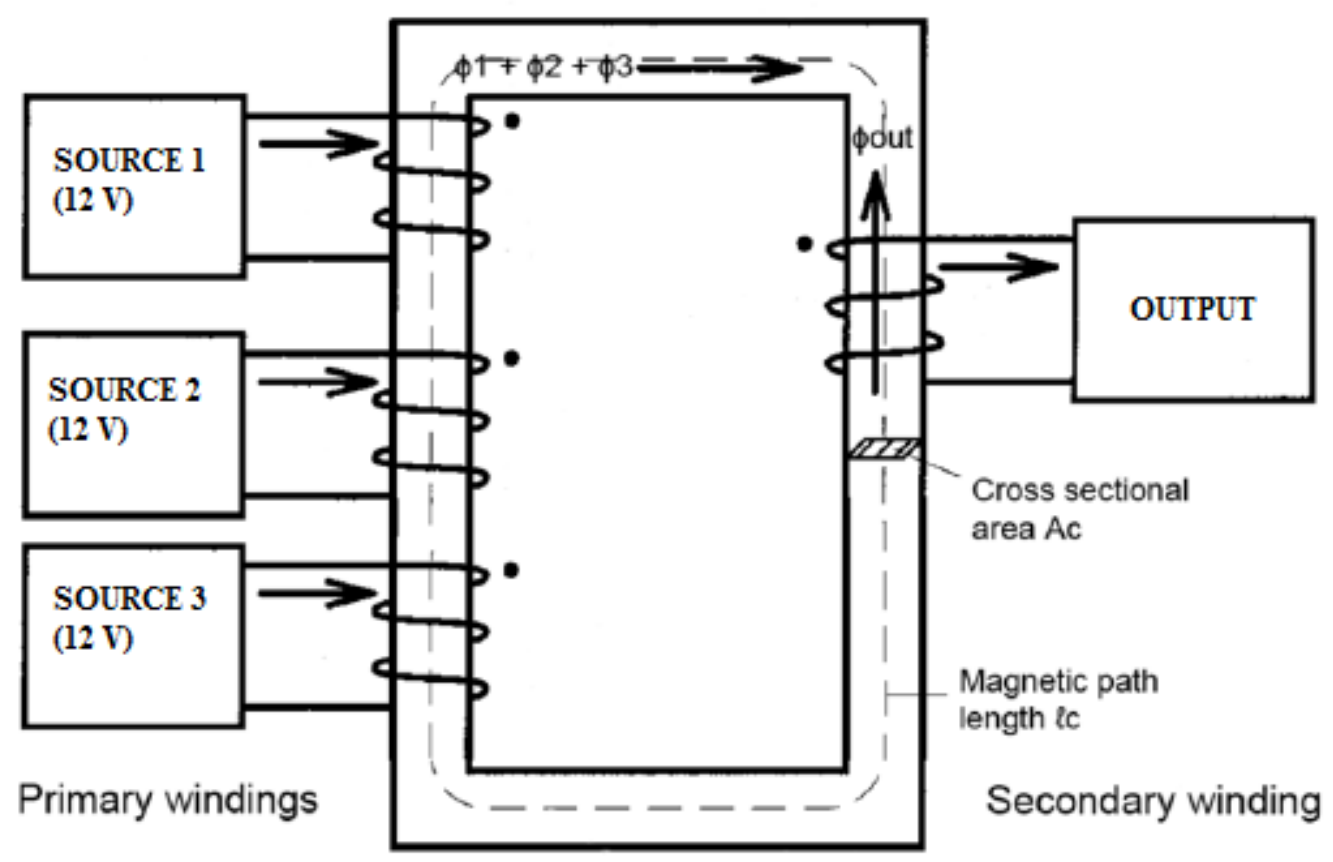

Figure 1-1: Multiple Input Single Output Transformer Diagram

According to Lenz's law a current is created by an induced voltage on the secondary side of the transformer that causes a flux opposing the original flux change. Therefore the output current of the secondary side correlates to the sum of the produced magnetic flux on the primary side [2] 


$$
\begin{gathered}
M M F=N_{1} I_{1}+N_{2} I_{2}+N_{3} I_{3}=\left(H_{1}+H_{2}+H_{3}\right) l_{c} \\
H=\frac{B}{\mu} \\
B=\frac{\Phi}{A_{C}} \\
M M F=\frac{\left(\Phi_{1}+\Phi_{2}+\Phi_{3}\right) l_{c}}{\mu A_{C}}
\end{gathered}
$$

Where:

$$
\begin{aligned}
& \text { N = Number of Turns on Primary Side } \\
& \text { I = Current on Primary Side } \\
& \text { H = Magnetic Field Intensity on Primary Side } \\
& B=\text { Magnetic Flux Density } \\
& A_{c}=\text { Cross sectional Area of the Transformer's Core } \\
& \Phi=\text { Magnetic Flux } \\
& \mu=\text { Magnetic Permeability of Core Material }
\end{aligned}
$$

Previous studies at Cal Poly done by Taffy Chi Kin Wong and Owen Jong have proven that it is possible to maintain a regulated output at high efficiency for high power applications using isolated topologies (full-bridge and flyback) [2][3]. By using the transformer to combine energy of the sources we are able to achieve isolation from input to output and draw power simultaneously from each source [1][3]. With the ability to combine multiple types of renewable sources obtaining power whenever and wherever becomes possible. 


\subsection{Objective}

The main objective of this thesis is to investigate and design a MISO using the flyback topology. Although, MISO converter concept is not new; however, the use of flyback for low wattage MISO has not been explored before. The main focus will be on the design, implementation, and testing of the MISO converter specifically made for charging USB devices. As mentioned before a $150 \mathrm{~W}$ power MISO converter using the flyback topology has been built with efficiency $\geq 80 \%$ at full load [3]. However, this topology ran into some difficulties with primary side being sensitive to short circuiting and noise around the sense pin. This thesis will explore, optimize and verify the flyback MISO converter for use in low power high efficient applications. In addition to designing the MISO on paper, computer simulations will be conducted to verify its operation and performance. Hardware implementation of the MISO converter will be performed to test its actual functionality and performance when charging a portable device. 


\section{Background}

\subsection{Purpose}

Technology evolves every year making life easier and more complicated at the same time. With inventions like laptops, smartphones, tablets, etc. the demand for readily available power has increased. As our resources diminish and pollution increases we need to look for greener ways to supply our energy needs. Advancements in renewables like solar, electric dynamo, wind, and hydro technology along-side with improvements in power electronics over the years has made it extremely easy for almost anybody to go online and find/ build a decently efficient renewable energy converter.

In developed countries like America finding a power source to charge your device is as easy as breathing air due to the readily available electrical power, however in developing countries it is not so simple. A developing country is "A country having a standard of living or level of industrial production well below that possible with financial or technical aid; a country that is not yet highly industrialized" [4]. Developing countries have a lot of areas where they lack industrialization and even electricity. In 2010 about 1.5 billion people or about a fifth of the world's population still had no access to electricity. However, with the drop in cost for solar panels, LEDs, and batteries people in these rural areas started to trade in their kerosene lamps and fires for this safer and more cost effective alternative [5][6]. With technology increasing in developing countries a problem arises with stable sources of power. With the abundant renewable energies like solar, wind, and hydro being available; utilizing and converting them into power sources would be the best option economically in addition it helps the earth to stay green. 
Designing a way to utilize renewable energies to a readily available and stable power source becomes a challenge. This thesis will focus on design and construction of a MISO converter for a low power mobile application to charge electronic devices such as tablets and smart phones anywhere renewable energy can be found. This project will greatly help people in these rural areas by providing a reliable, greener, and cost effective energy converting solution. 


\subsection{Concept}

The general idea is to design and construct a converter that takes in different types of renewable energies that will combine and convert them into a single useable output. Figure 2-1 shows a block diagram of an overall MISO system. The block diagram shows four different types of renewables (solar, bicycle dynamo, wind, and hydro) going into their out $12 \mathrm{~V}$ DC stage. The $12 \mathrm{~V}$ DC stage converts the renewables into a regulated $12 \mathrm{~V}$ output that will then be combined in the converter. It is necessary for the sources to all be DC in order for the converter to work. The regulated inputs all need to be $12 \mathrm{~V}$ because if the voltages are too different it will cause complication in the converter.

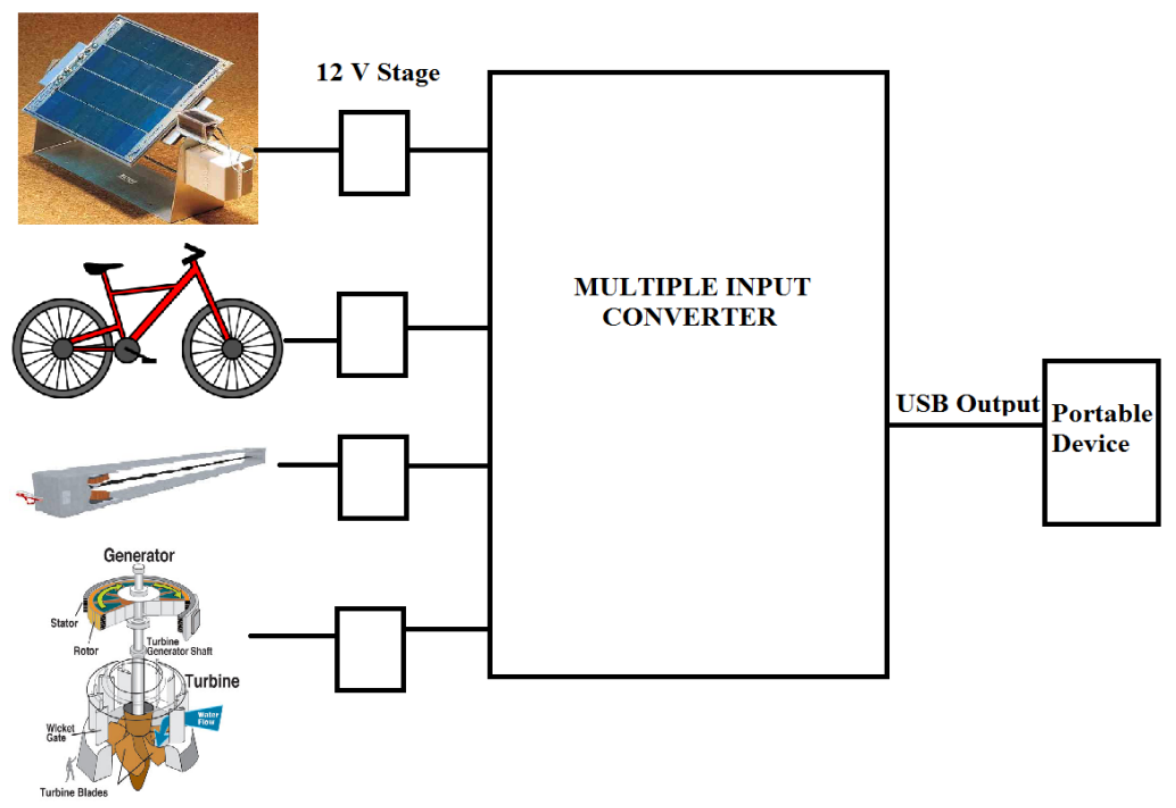

Figure 2-1: Overall System Block Diagram 


\subsection{Renewable Power Sources}

\subsubsection{Solar Power}

The Sun is essential to all life on earth; if it was not there we would just be a cold dark uninhabitable ball of rock. The sun causes the tide in the ocean, provides the necessary gravity to keep the earth in place, creates different weather, generates heat, produces light, and energy. With the advancement in solar power humans have been able to harness the power of the sun's rays and convert them into useable electrical energy. Like how plants absorb sunlight to mix with $\mathrm{CO}_{2}$ to generate their own internal energy and grow [7].

Photovoltaic Cells (PV) converts sunlight directly into electricity. These cells can be combined and packaged in a frame making a solar panel. These cells are made up of special material called semiconductors, the most common one being silicon.

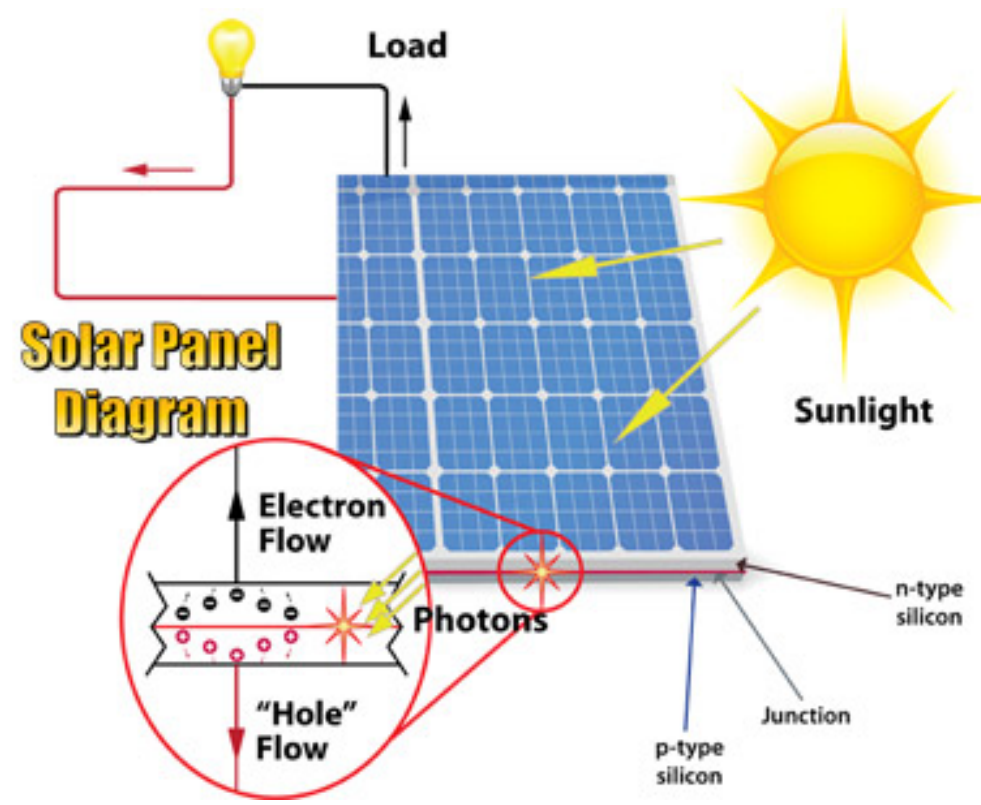

Figure 2-2: Etap, Solar Panel Diagram [9] 
As seen in Figure 2-2 solar panels basically work when sunlight hits the PV cells where some of the light is absorbed. The absorbed light knocks free electrons and associated holes in the semiconductor material. The newly freed electrons are affected by the PV cells electric field causing them to move or make what is better known as current. With metal contacts on the solar panel we can then make use of the current for external applications like charging a battery or powering LED lights [8].

\subsubsection{Electric Dynamo}

The dynamo works by using a rotating conductor, usually copper wires, in a magnetic field to generate electric current.

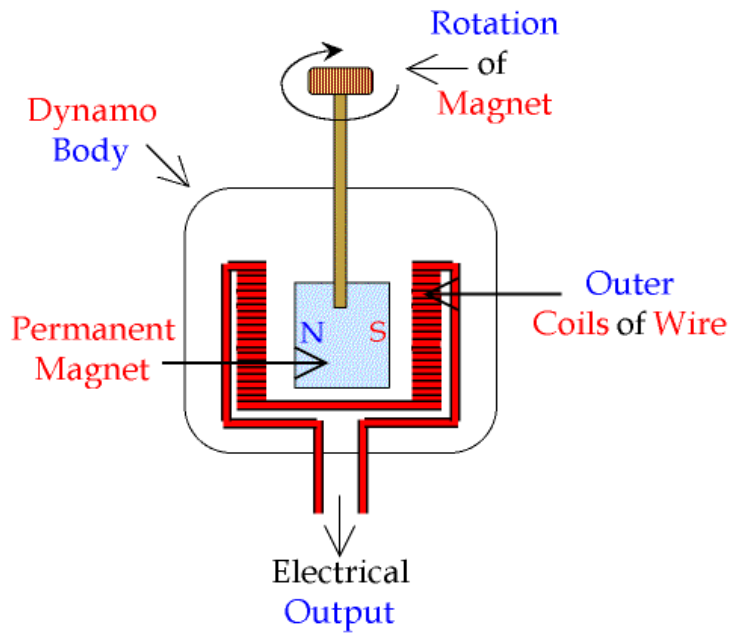

Figure 2-3: Bicycle Dynamo [11]

This theory was first discovered by Faraday in 1831 [10]. Faraday's principal states:

"When a conductor is moved in a field of magnetic force in any way so as to cut the lines of force, there is a electromotive-force produced in the conductor, in a direction at right angles to 
the direction of motion, and at the right angels also to the direction of the lines of force, and to the right of the lines of force, as viewed from the point from which the motion originates." [10]

In simple terms a dynamo-electric machine takes mechanic motion and converts it into current [10]. The use of electric dynamos can be used as either a motor or generator. For years people have been using these machines to generate electricity driven by water turbines, gas or diesel engines, and even in a simple bicycle light generator. However, in this thesis, the dynamo will be used in conjunction with a human power generator, such as the hand cranking generator.

\subsubsection{Wind Energy}

When you think of wind most likely electricity or power doesn't come to mind. For centuries humans have harnessed the power of wind to pump water or crush grain with the use of wind mills. Now days these simple wind mills have evolved into wind turbines to harness the power of electricity. By the end of 2011 United States' wind capacity reached 47,000M Watts and has grown to 50,000M Watts, which is enough energy to power over 12 million homes [12].

Wind is created when there is an uneven heating of the earth's atmosphere caused by the sun [13]. Wind energy is harnessed through the power of a wind turbine. The wind turbine is basically a fan that works in reverse; where wind generates electricity instead of taking electricity to create wind. The wind moves the propellers on the turbine around a rotor, which is connected to the main shaft causing a generator to spin and make electricity [14]. 


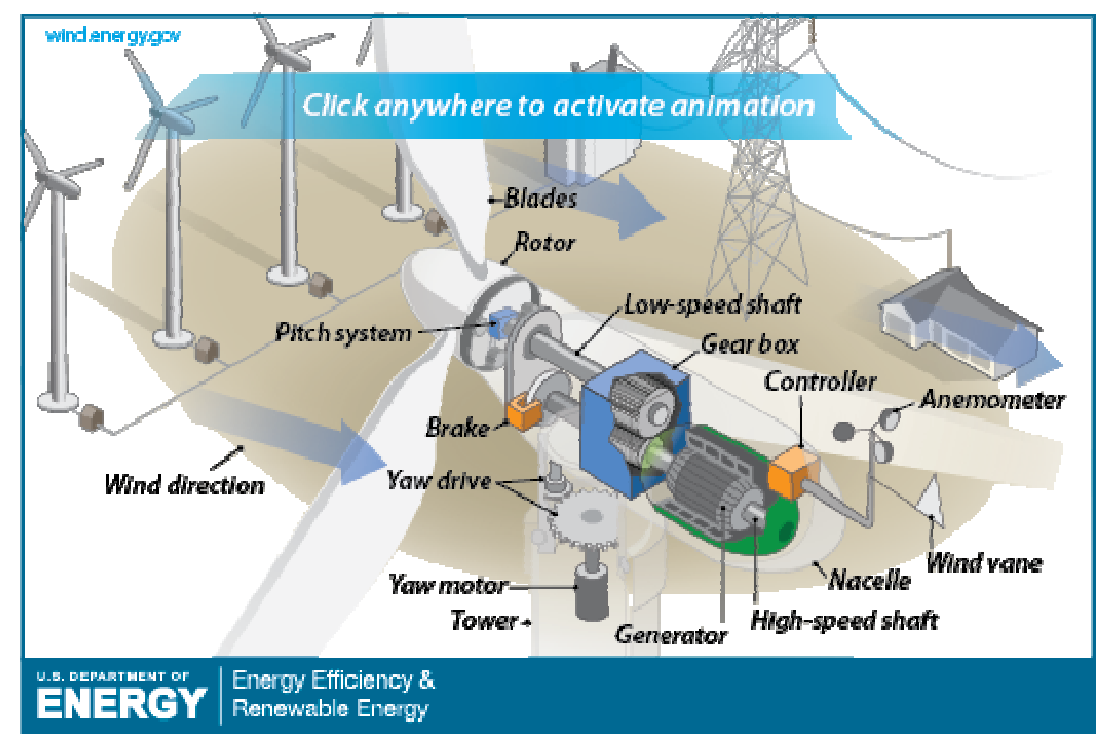

Figure 2-4: Inside of a Wind Turbine [14]

\subsubsection{Hydro Electric Energy}

Harnessing the power of water has been used for many centuries. Now days with hydropower turbines it has become possible to utilize water to generate electricity. Hydropower taps into the water cycle harvesting its energy to produce electricity. Hydropower is considered a renewable energy because the water cycle is endless constantly recycling itself. The term hydropower is used when the flow of water is harnessed and converted into electricity [15]. 


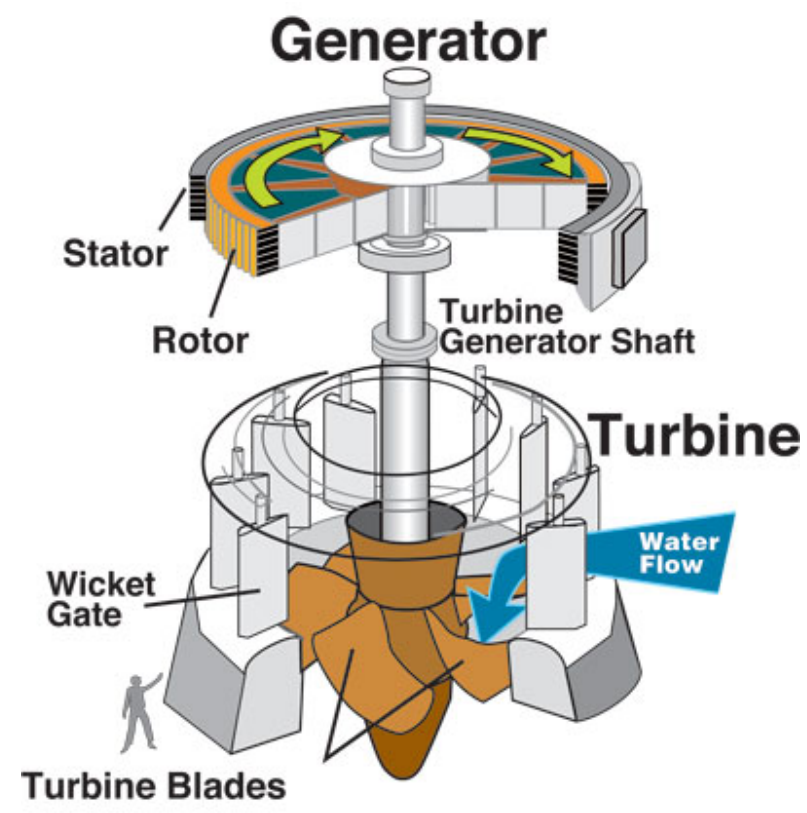

Figure 2-5: Hydroelectric Generator [16]

In order to convert hydropower into electricity a turbine/ generator is needed. The kinetic energy of the flowing water is used to rotate the turbines blades, which spins the shaft in an electric generator to produce electricity [16]. 


\subsection{Flyback Topology}

The flyback converter is one of the most used topologies for low power applications because of its low cost, simplicity, and is designed to isolate the load from the source. The isolation comes from the transformer which also combines the output inductor and transformer into a single element. However, the flyback converter is known for low efficiency, large output capacitor, and high current stress. The flyback topology inefficiency comes from the switching losses in the switch and output diode, large transformer core, high eddy-current losses, and electromagnetic interference [17] [18]. A flyback transformer is not like your typical transformer where ideally it transfers the energy from the primary to the secondary instantaneously without any storage. Instead the flyback is more like individual inductors on the same core.

The flyback topology has three modes of operation: continuous conduction mode (CCM), discontinuous conduction mode (DMC), and transition mode (TM) or also known as boundary conduction mode (BCM). Each mode has advantages and disadvantages as listed in Figure 2-5. For this project it was decided to utilize BCM mainly because it allows for the use of a smaller transformer, which helps keep cost and board size down. Also, BCM improves overall efficiency of the flyback converter. However, BCM limits the transformer's DC current which may cause the need for higher transformer inductance. 


\begin{tabular}{|c|c|c|}
\hline $\begin{array}{l}\text { Operating } \\
\text { Mode }\end{array}$ & Advantages & Disadrantages \\
\hline CCMI & $\begin{array}{l}\text { - Small ripple and ms curreat } \\
\text { - Lower MOSFET conduction loss } \\
\text { - Lower primary MOSFET tum-off loss } \\
\text { - Low core loss } \\
\text { - Better cross-egulation } \\
\text { - Lower capacitor dissipation } \\
\text { - Smaller EMI filter and output filter } \\
\text { - Constant switching frequency }\end{array}$ & $\begin{array}{l}\text { - Slope compensation required at higher duty } \\
\text { cycles (Peak CMC) } \\
\text { - Diode reverse-recovery loss } \\
\text { - Higher voltage stress for secondary diodes } \\
\text { - RHPZ } \\
\text { - Synchronous-rectifier subber loss } \\
\text { - Low hight-load efficiency }\end{array}$ \\
\hline DCMI & $\begin{array}{l}\text { - No diode reverse recovery loss } \\
\text { - Slope compensation not required in CMC* } \\
\text { - No RHPZ problem } \\
\text { - Lower inductance may allow smaller } \\
\text { transformer size } \\
\text { - First-order system even in VMC' } \\
\text { - Constant switching frequency }\end{array}$ & $\begin{array}{l}\text { - Large ripple and peak current } \\
\text { - Higher MOSFET conduction loss } \\
\text { - Higher core loss } \\
\text { - Higher primary MOSFET tum-off loss } \\
\text { - Higher capacitor dissipation } \\
\text { - Higher MOSFET voltage stress } \\
\text { - Large EMI filter and output filter }\end{array}$ \\
\hline $\mathrm{TM}(\mathrm{BCM})$ & $\begin{array}{l}\text { - No diode reverve-tecovery loss } \\
\text { - Soft turn-on switching possible-MOSFETs } \\
\text { with lower Ros(e) can be used } \\
\text { - No secondary sabber loss } \\
\text { - Slope compensation not required } \\
\text { - No RHPZ problem } \\
\text { - First-order system } \\
\text { - Transieat response } \\
\text { - Lower inductance may allow smaller trans- } \\
\text { former size }\end{array}$ & $\begin{array}{l}\text { - Large ripple and peak current } \\
\text { - Higher core loss } \\
\text { - Higher primary MOSFET tum-off loss } \\
\text { - Higher MOSFET conduction loss" } \\
\text { - Higher capacitor disipation } \\
\text { - Large EMI filter and output filter } \\
\text { - Variable switching frequency } \\
\text { - Primary MOSFET voltage stress may be higher }\end{array}$ \\
\hline
\end{tabular}

Figure 2-6: Comparison between CCM, DCM, and TM for a Flyback Power Supply [17]

The flyback operates with two states: when the switch is "on" (Closed) and when the switch is "off" (Open) as seen in Figure 2-6 on the next page. 

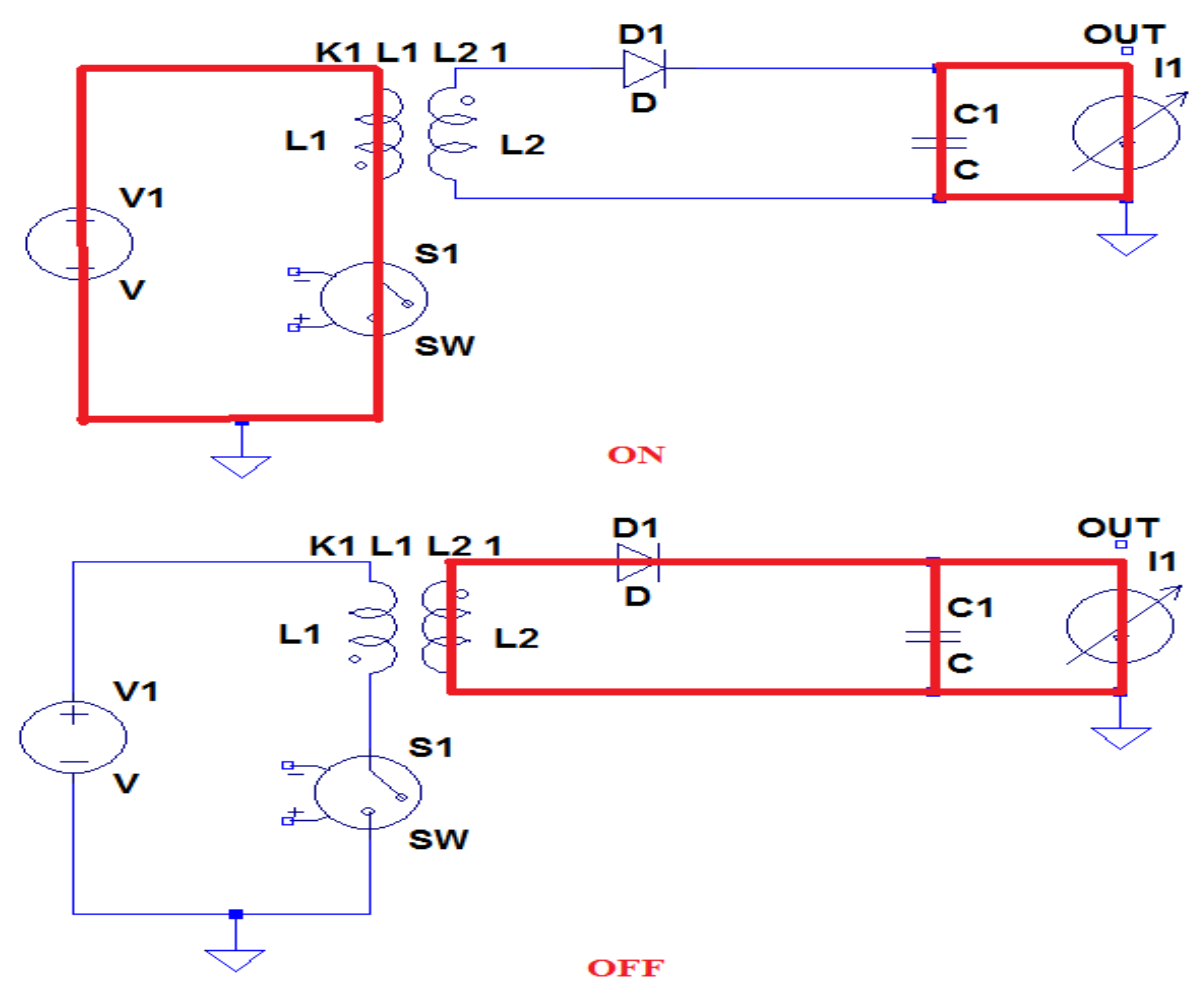

Figure 2-7: Two States of a Flyback Converter (When the Switch is Closed (ON) and When it is Open (OFF)

When the switch is "on" the current from the source is fed into the primary side of the transformer where the energy is stored as magnetic flux in the core at the rate of input voltage over magnetizing inductance $(\mathrm{V} / \mathrm{L})$. At the same time the output diode is reversed biased and the output is fed by the output capacitor to maintain to constant load. Once the switch is open or "off" the diode become forward biased and the magnetic flux is transferred to the secondary side where it feeds the load and charges the capacitor back up to be used for the next cycle. 


\subsection{USB Charging}

The USB (Universal Serial Bus) was designed to transfer data between devices. Today the most common USB ports are USB 2.0 and 3.0. The main difference between the two is data transfer rate and their specifications. USB 2.0 runs off of $5 \mathrm{~V}$ at $500 \mathrm{~mA}$ while USB 3.0 uses $5 \mathrm{~V}$ at $900 \mathrm{~mA}$. However, with the advancement of technology the USB port is now being used as a low power source as long as it meets certain USB specifications. By using the USB port as a source it has become possible to use any computer or USB charger to charge mobile device, like a tablet or smartphone. This section will look into the USB 2.0 specification since this USB version was decided for this project. At a glance the USB 2.0 power requirements can be seen in the table below, however a full table can be seen in [19].

Table 2-1: USB Power Requirements [19] [20]

\begin{tabular}{|c|c|c|c|}
\hline \multicolumn{2}{|c|}{ Parameter } & Min & Max \\
\hline Voltage & Low Power Device & $4.4 \mathrm{~V}$ & $5.25 \mathrm{~V}$ \\
\hline Voltage & High Power Device & $4.75 \mathrm{~V}$ & $5.25 \mathrm{~V}$ \\
\hline \multicolumn{2}{|c|}{ Max Low Power Current } & & $100 \mathrm{~mA}$ \\
\hline \multicolumn{2}{|c|}{ Max High Power Current } & & $500 \mathrm{~mA}$ \\
\hline \multicolumn{2}{|c|}{ Nominal Output Power } & & $2.5 \mathrm{~W}$ \\
\hline
\end{tabular}

To connect a device to a USB host it must be configured or follow the rules of suspend as seen in Table 2-2. However, if the device is connected to a charging port (USB charging configuration) it can bypass the configurations/ the rules of suspend and charge directly [19].

Table 2-2: Load Device Requirements Using a Standard Downstream Port [19]

\begin{tabular}{|c|c|}
\hline Current Drawn & Condition \\
\hline $2.5 \mathrm{~mA}$ & The bus is suspended \\
\hline $100 \mathrm{~mA}$ & The bus not suspended and not configured \\
\hline $500 \mathrm{~mA}$ & The bus is not suspended but configured \\
\hline
\end{tabular}


Different configurations have been created so a device can figure out if it is connected to a USB Charger or Standard Downstream Port (SDP). A USB Charger is considered as Accessory Charger Adaptor (ACA), Charging Downstream Port (CDP), and Dedicated Charging Port (DCP).

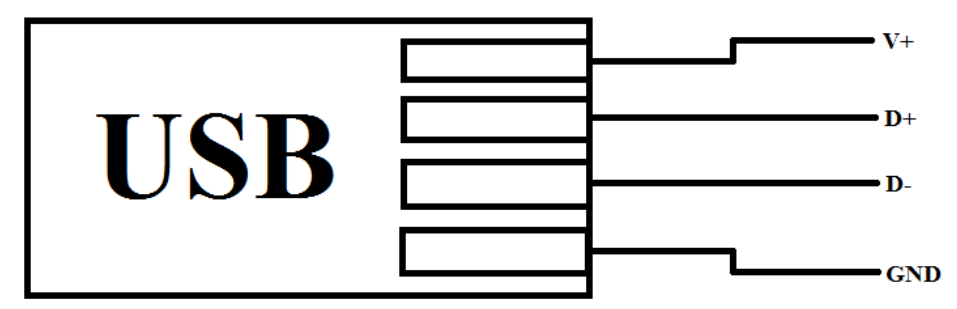

Figure 2-8: USB Diagram

USB ports have their data lines (D+ and D-) configured in a certain order, so the device can recognize which type it's connected to. In Table 2-3 you can see the data line configurations.

Table 2-3: USB Data Line Configurations

\begin{tabular}{|c|c|}
\hline Type & Configuration \\
\hline Standard Downstream Port (SDP) & Pulls D+/D- to GND through two $15 \mathrm{k} \Omega$ resistors \\
\hline Accessory Charging Adaptor (ADA) & Has unique ID resistances for each type \\
\hline Charging Downstream Port (CDP) & Voltage $\mathrm{V}_{\mathrm{DM} \text { SRC }}$ on D- when $\mathrm{V}_{\mathrm{DAT} \text { REF }}<\mathrm{V}$ on $\mathrm{D}+<\mathrm{V}_{\mathrm{LGC}}$ \\
\hline Dedicated Charging Port (DCP) & D+ and D- shorted together or left open \\
\hline
\end{tabular}




\section{Design Requirements}

As stated previously the purpose of this project is to redesign and optimize the previously designed MISO converter for a mobile USB charger, while using easily obtained off the shelf parts and maintaining its high efficiency. The MISO converter is designed while keeping in mind that it is meant to be used in rural areas; so keeping it low-cost, portable, and easily reproduced is essential. This project will use all commercial parts except for the custom PCB for easy adoption of the converter and to keep its cost minimum. All the sources (solar panel, bicycle dynamo, DC wind turbine, and hydro turbine) should be all off the shelf products as well. For practicability it will be assumed that the sources will produce at least $4 \mathrm{~W}$ at $12 \mathrm{~V}$ output, which means the nominal input voltage of the MISO will be $12 \mathrm{~V}$. Since USB 2.0 connection will be used to charge the device, the MISO converter will have a regulated output voltage of $5 \mathrm{~V}$ and provide $0.5 \mathrm{~A}$ producing a max power of $2.5 \mathrm{~W}$.

USB 2.0 connection was decided on because having USB charging is more versatile, so the converter can charge any USB device such as smartphones and is not limited to just one device. All these electronic devices are sensitive and hold a lot of important information so isolation is required. A transformer is ideal for this application because it provides isolation, step up or down function, and provides a way to combine multiple sources. This topology has proven that it is possible to achieve high efficiency, so the MISO should operate at $\geq 80 \%$ efficiency at maximum load. The MISO converter should have line regulation be $\leq 3 \%$ and load regulation should be less than $3 \%$ as well when load is changed from $10 \%$ to $90 \%$ and vice versa. Also, to guarantee that the output voltage quality is up to par; the output peak-to-peak voltage ripple at full load and nominal input should be less than $2 \%$ (of 5V). Table 3-1 shows a summary of the 
design requirements of the proposed MISO Converter as seen from the block diagram in Figure $2-1$.

Table 3-1: Summary of Design Requirements of MISO Converter

\begin{tabular}{|c|c|}
\hline Requirement & Value \\
\hline Number of Sources & 3 \\
\hline Source Power (Min) & $4 \mathrm{~W}$ \\
\hline Source Input Voltage & $\mathbf{1 2 V}$ \\
\hline Connection Type & USB 2.0 \\
\hline Maximum Output Wattage & $\mathbf{2 . 5 \mathrm { W }}$ \\
\hline Output Voltage & $\mathbf{5 V}$ \\
\hline Line Regulation & $\leq 3 \%$ \\
\hline Load Regulation & $\leq \mathbf{3 \%}$ \\
\hline Output Voltage Peak-to-Peak Ripple & $\leq \mathbf{2 \%}$ \\
\hline Efficiency at Full Load & $\geq \mathbf{8 0 \%}$ \\
\hline
\end{tabular}




\section{Design and Simulation}

There are multiple advantages of designing a low power high efficient MISO using the flyback topology. When trying to keep cost and complexity of a converter down the flyback topology is ideal due to its low part count, e.g. it only needs one winding and one main switch per given input. This also makes it easy to find off the shelf components making it easily scalable and reproducible. However, the flyback topology is known for its lower efficiency compared to other isolated topologies mainly because its uses of the transformer as an energy storage device instead of an energy transfer device. Also, the flyback topology is more prone to high switching voltages spikes caused by leakage inductance form the transformer, therefore affecting the maximum drain-to-source voltage requirement of the MOSFETs which may further require a higher voltage device or the use of snubber circuit. Lastly, the flyback topology lacks output inductor and hence it requires the use of relatively large output capacitor due to its inherently large peak to peak output voltage and current ripples.

As stated before the flyback topology is just as in any other DC-DC converter topologies and can be operated in different conduction modes: Continuous Conduction Mode (CCM), Discontinuous Conduction Mode (DCM) and Boundary Conduction Mode (BCM). By using the boundary conduction mode (BCM) it becomes possible to improve the overall efficiency of the flyback converter. This is mainly acquired from reducing switching losses of both the main switch and the output diode. Typically BCM is maintained by a variable frequency current mode switching scheme that has the switch turn back on when the secondary side current hits zero, helping reduce switching losses. By returning the secondary current to zero every cycle, the parasitic resistive voltage drops do not cause load regulation errors. BCM also allows for a 
smaller transformer which will help with board space and size [21]. However, since BCM limits transformer's DC current it may therefore cause high peak-to-peak transformer current ripple which translates into higher transformer's inductance requirement, or if neglected will cause large RMS losses.

As stated in the previous chapters when the switch is "on" or conducting the current from the source flows into the transformer's primary side while the output diode is reverse biased, forcing energy to be stored as magnetic flux in the transformer. Once the switch is "off" while the output diode is forward biased and the flux is transferred to the secondary side to the output capacitor and load. However, because the main switch is in series with the primary winding, some energy will be stored in the leakage inductance of the transformer. The leakage inductance is a self-inductance, which is not coupled to any other inductance and thus it creates a problem when its current is interrupted. Unfortunately its current is indeed interrupted as soon as the main switch is turned off. This is a problem known as the leakage spike, which appears as additional voltage spike across the main switch. This leakage spike may be significant and a snubber circuit is typically employed to help suppress this spike.

Keeping in mind that the converter needs to be low cost, small, and easily reproduced, the LT3748 controller from Linear Technology was chosen. The LT3748 is ideal because it operates in BCM to increase overall converter's efficiency. Also, it allows for primary side sensing which maintains isolation, but eliminates the need for an extra transformer winding or optoisolator, hence reducing complexity, cost, and board space. This controller also allows for a wide range of maximum output power based on the components used. 
The LT3748 regulates the output voltage by a couple of resistors $\left(\mathrm{R}_{\mathrm{FB}}\right.$ and $\left.\mathrm{R}_{\mathrm{REF}}\right)$ as seen in Figure 4-1. The ratio of both resistor values will determine the output voltage. Based on LT3748 datasheet, $R_{R E F}$ is suggested to be $6.04 \mathrm{~K} \Omega$ which gives $R_{F B}=25.5 \mathrm{~K} \Omega$. Before we can go any further we must figure out the transformer's turn ratio and inductance. The transformer is probably the most critical part to the success of the converter. Since the voltage on the secondary side is inferred on by the primary side voltage the transformer's turn ratio must be tightly controlled.

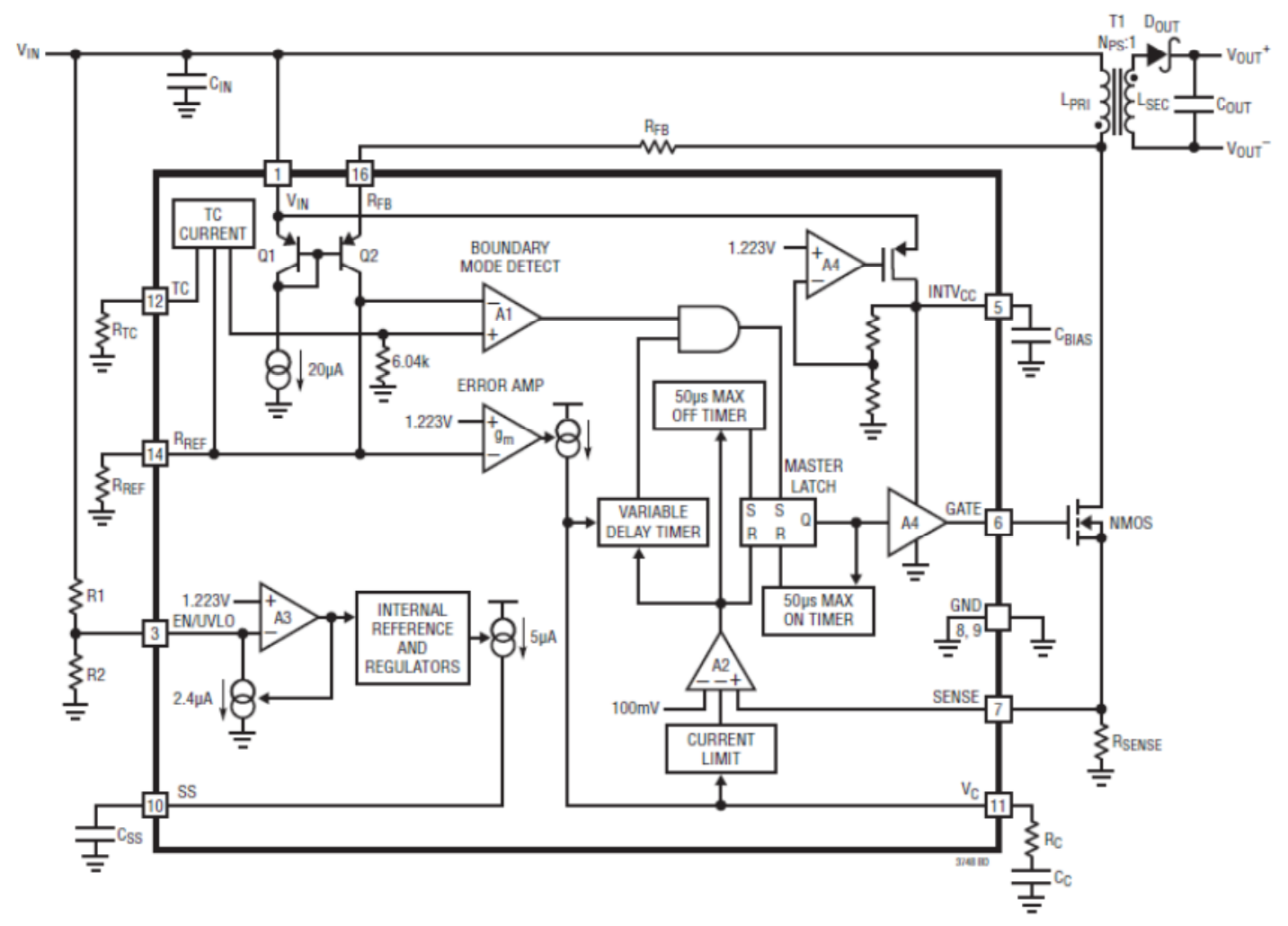

Figure 4-1: LT3748 Block Diagram [21]

When considering a transformer's turn ratio we must keep in mind the current and voltage limitation on both sides of the transformer. In order to draw maximum power from the input to output the current and voltage limitations need to be balanced. In addition, duty cycle will also 
need to be chosen in conjunction with the turn ratio to ensure minimum amount of losses.

Consider $\mathrm{N}$ to be a positive integer greater than one, and duty cycle $\mathrm{D}$ less than one. Then ideally, both values will have to be iterated to yield the most optimum operation of the converter.

However, for this thesis due to the difficulty in obtaining a commercially available transformer with the ideal turn ratio, it was decided to utilize a transformer with a 1:1 turn ratio.

Given the 1:1 turn ratio we can figure out the minimum inductance of the transformer, nominal voltage rating on the MOSFET, reverse breakdown voltage of the output diode, duty cycle, and current limit of the transformer through the following equations:

Transformer Turn Ratio Section:

$$
\begin{array}{r}
N_{P S}=\frac{N_{P}}{N_{S}} \\
N_{P S}=\frac{1}{1}=1
\end{array}
$$

MOSFET Selection:

$$
\begin{gathered}
V_{D S(M A X)} \geq V_{I N(M A X)}+V_{O U T} * N_{P S} \\
25 V=V_{D S(\text { MAX })} \geq 20+5 * 1
\end{gathered}
$$

This value is assumed with no leakage inductance, however even the smallest amount of leakage inductance can cause the MOSFET to ring to double the expected voltage so generally it's a good idea to multiply this value by three. Also, the current of the MOSFET should have a margin of about double of what the transformer on the primary side sees. 
OUTPUT Diode Selection:

$$
\begin{gathered}
V_{R(D I O D E)} \geq \frac{V_{I N(M A X)}}{N_{P S}}+V_{O U T} \\
25 V=V_{R(D I O D E)} \geq \frac{20}{1}+5
\end{gathered}
$$

Same with the output diode it is good practice to multiply this value by three to prevent the use of a snubber circuit.

Duty Cycle Calculation:

$$
\begin{aligned}
& D=\left(V_{\text {OUT }}+V_{F(D I O D E)}\right) * \frac{N_{P S}}{V_{I N}+\left(V_{O U T}+V_{F(D I O D E)}\right) * N_{P S}} \\
& 0.314=D=(5+0.5) * 1 /((12+(5+0.5) * 1)
\end{aligned}
$$

Peak Current of Primary Side:

$$
\begin{gathered}
I_{L I M} \approx 2 * \frac{I_{O U T(M A X)}}{0.85 *(1-D) * N_{P S}} \\
1.715 A \approx I_{L I M} \approx 2 * \frac{0.5}{0.85 *(1-0.314) * 1}
\end{gathered}
$$

RSENSE Calculations:

$$
\begin{gathered}
R_{\text {SENSE }}=\frac{100 \mathrm{mV}}{I_{\text {LIM }}} \\
58 \mathrm{~m} \Omega=R_{\text {SENSE }}=\frac{100 \mathrm{mV}}{1.715}
\end{gathered}
$$

*Note: $\mathrm{R}_{\text {sense }}$ may need to be adjusted to increases output power and lower sense voltage 
PRIMARY INDUCTANCE Calculation:

$$
\begin{gathered}
L_{P R I} \geq V_{I N(M A X)} * R_{S E N S E} * \frac{200 n s}{15 m V} \\
15 \mu H=L_{P R I} \geq 20 * 56 m * \frac{200 n s}{15 m V} \\
L_{P R I} \geq\left(\left(V_{\text {OUT }} * V_{F(D I O D E)}\right) * R_{S E N S E} * 400 n s * N_{P S}\right) / 15 m V \\
8 \mu H=L_{P R I} \geq((5 * 0.5) * 56 m * 400 n s * 1) / 15 m V
\end{gathered}
$$

From the equations above in order to keep a 1:1 turn ratio it is necessary to choose a transformer that has an inductance $\mathrm{L} \geq 15 \mu \mathrm{H}$. After consideration of minimum inductance value, lower operating frequency to reduce switching losses, and what was available the VERSA-PAC VPH5-0155-R was chosen. When combining inductors they follow the same rules as resistors, however, when attached to the same core the rules change. When in series it is necessary to take into account the square factor. In parallel the inductance stays the same but increases the amount of current carrying capability [22].

Series Inductance: $L_{T O T A L}=L_{B A S E} * S^{2}$

Series Current: $I_{\text {TOTAL }}=I_{B A S E} * P$

Parallel Inductance: $L_{T O T A L}=L_{B A S E} * S^{2}$

Parallel Current: $I_{\text {TOTAL }}=I_{B A S E} * P$

Where:

$\mathrm{L}_{\mathrm{BASE}}=$ Inductance of a single winding

$\mathrm{P}=$ Number of windings in parallel (use 1 when all in series)

$\mathrm{S}=$ Number of windings in series

$\mathrm{I}_{\mathrm{BASE}}=$ Max Current rating of one winding 
Having chosen the transformer/ inductor value $(22.3 \mu \mathrm{H})$ the switching frequency can be estimated as:

$$
\begin{gathered}
F_{S W} \approx \frac{V_{I N(M A X)} *\left(V_{O U T}+V_{F(D I O D E}\right) * N_{P S}}{L_{P R I} * I_{L I M(M I N)} *\left(V_{O U T}+V_{F(D I O D E} * N_{P S}+V_{I N(M A X)}\right)} \\
98.6 k H z \approx F_{S W 12 V} \approx \frac{12 *(5+0.5) * 1}{22.3 \mu * 1.715 *(5+0.5 * 1+12)}
\end{gathered}
$$

As stated before the output voltage is controlled by a couple of resistors. Looking at the block diagram in Figure 4-1 it can be implied that the voltage across $\mathrm{R}_{\mathrm{FB}}$ is $\mathrm{V}_{\mathrm{OUT}}$ because the voltage seen at pin 16 is the reflected voltage from pin 1 due to the biasing circuitry/ PN junction characteristics and the voltage seen at the other node (in between the primary side winding and the drain of the MOSFET) is $\mathrm{V}_{\mathrm{IN}}+\mathrm{V}_{\mathrm{OUT}}$. The current through $\mathrm{R}_{\mathrm{FB}}$ is set by the comparator's reference voltage and $R_{R E F}$, which then can be used to find $R_{F B}$.

$$
\begin{gathered}
\frac{1.223 \mathrm{~V}}{6.04 \mathrm{~K}}=0.2025 \mathrm{~mA} \\
24.7 \mathrm{~K} \Omega \approx R_{F B} \approx \frac{5 \mathrm{~V}}{0.2025 \mathrm{~mA}}
\end{gathered}
$$




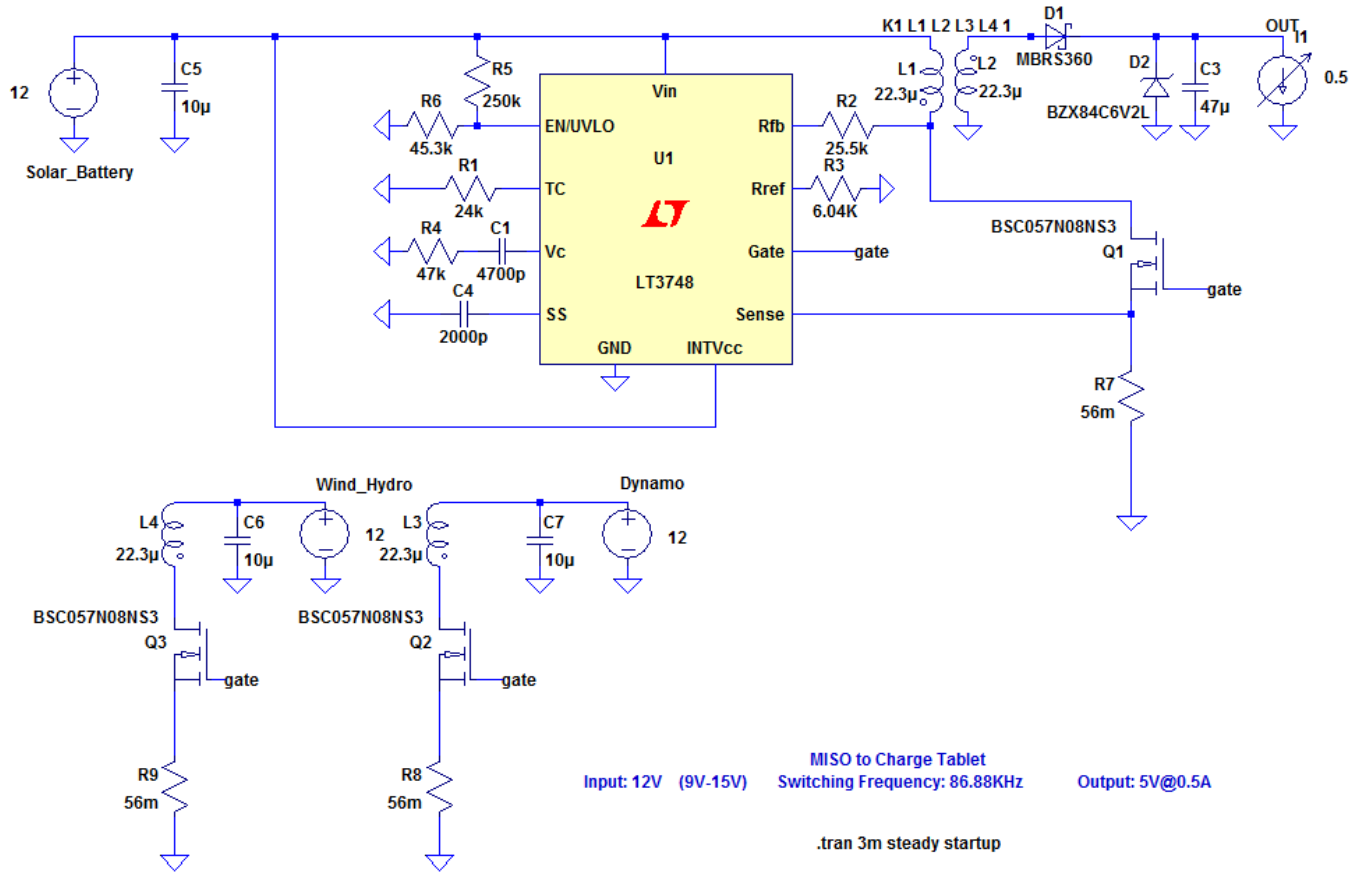

Figure 4-2: MISO Flyback Converter Schematic

Due to the limitation of the transformer the output required paralleling three of the six inductor pairs leaving three for the input. This means that the "or diode" configuration in the previous design was unnecessary if we wanted three different input sources because there are not enough terminals. Therefore, it was decided to have the solar/ battery combination source be the primary source because it has the ability to be constantly on as long as the battery is charged. Eliminating the need to set a primary source with the use of the "or diode" configuration. In addition this greatly reduced amount of parts, board space, and cost. 


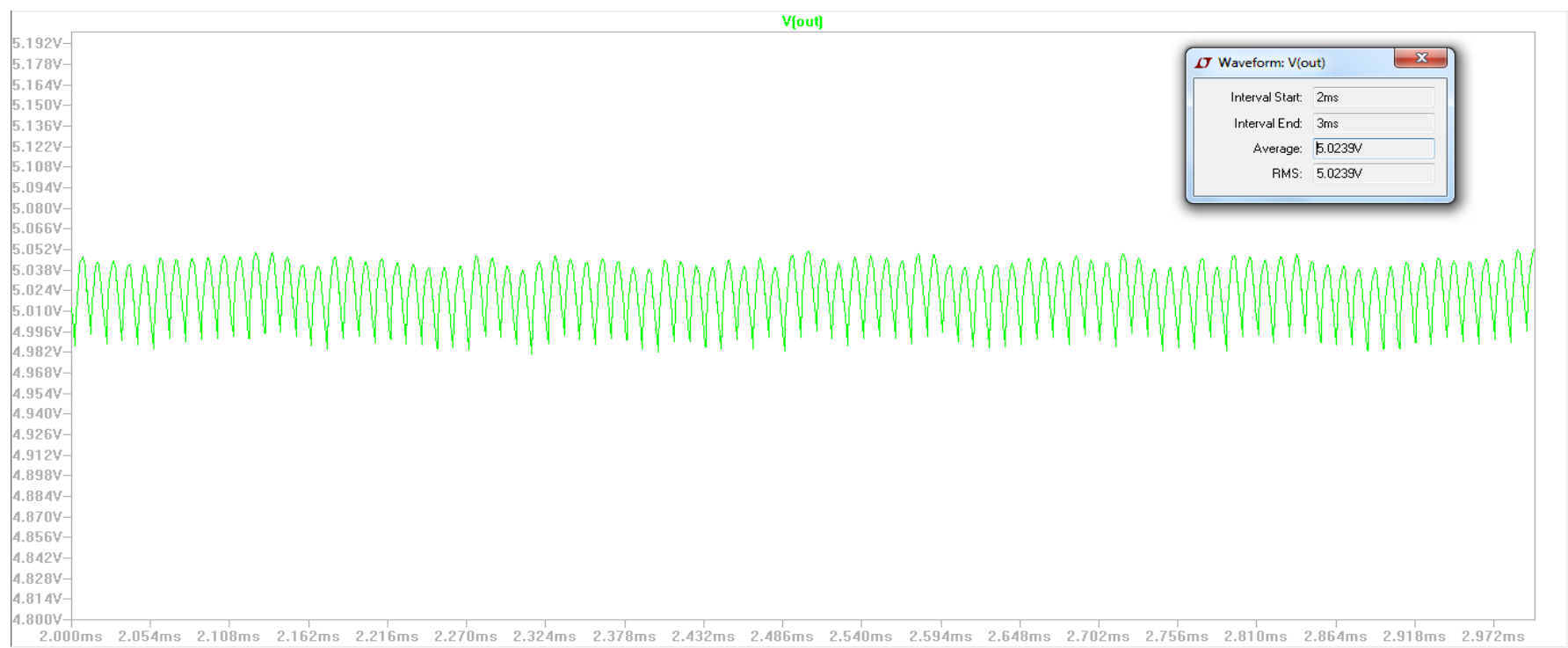

Figure 4-3: Regulated 5V Output with 500mA Load
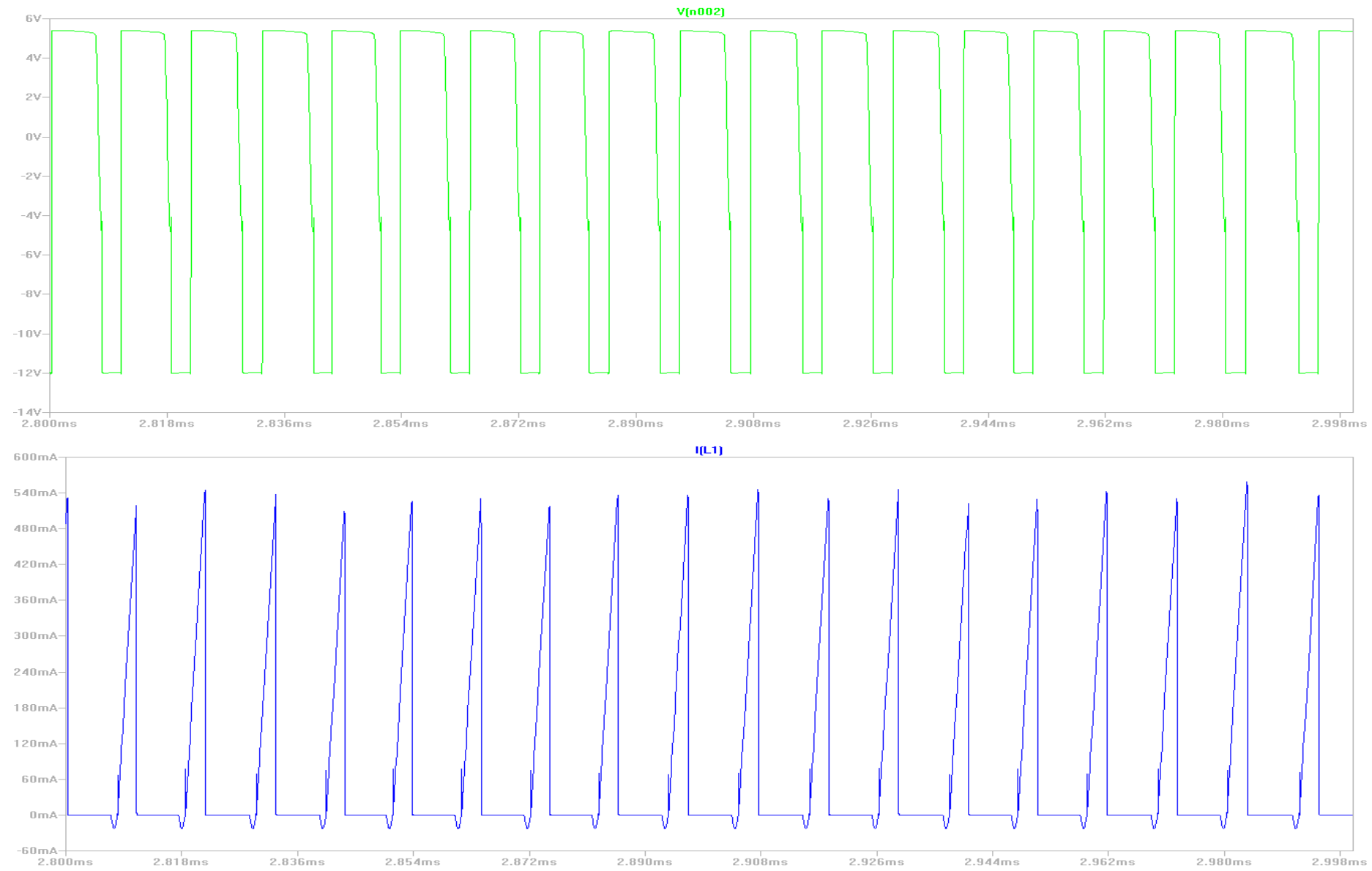

Figure 4-4: MISO Converter Secondary Winding Current and Switching Node 
From Figure 4-3 it can be seen that the output voltage (5.02V) is within range of USB 2.0 specification for $500 \mathrm{~mA}$ load $(4.75 \mathrm{~V}-5.25 \mathrm{~V})$. Also, from the simulation it was seen that the output peak to peak ripple is about $1.12 \%(4.996 \mathrm{~V}-5.056 \mathrm{~V})$. Looking at current through the transformer in the simulations it was seen that it would not saturate the chosen transformer with the paralleled configuration. Finally, in Figure 4-4 it was measured that the switching frequency is about $92.5 \mathrm{kHz}$, which is relatively close to what was calculated. Based on the calculations and simulations done we can proceed in choosing VERSA-PAC VPH5-0155-R and build the MISO converter. 


\section{Hardware and Results}

\subsection{Hardware}

Since all parts are commercial off the shelf products it was not necessary to worry about certain parts like the transformer meeting certain tolerance and quality since all the parts have been thoroughly designed, tested, and guaranteed by their manufacture. Based on the schematic in Figure 5-1 a two layer custom printed circuit board (PCB) was designed to ensure a quality designed circuit. However, it was discovered that Rev. 1 of the PCB layout had some problems causing the MISO to not fully work. The cause was due to the lack of different input and output capacitors types, but more importantly the location of the sense resistor and tightness of circuit loops. It was found out that the location of the grounded part of the sense resistor was too far from the chip and was not isolated enough causing noise at the sense pin, therefore a new schematic and PCB layout, Rev. 2, was created as seen in Figure 5-2 and 5-3. 


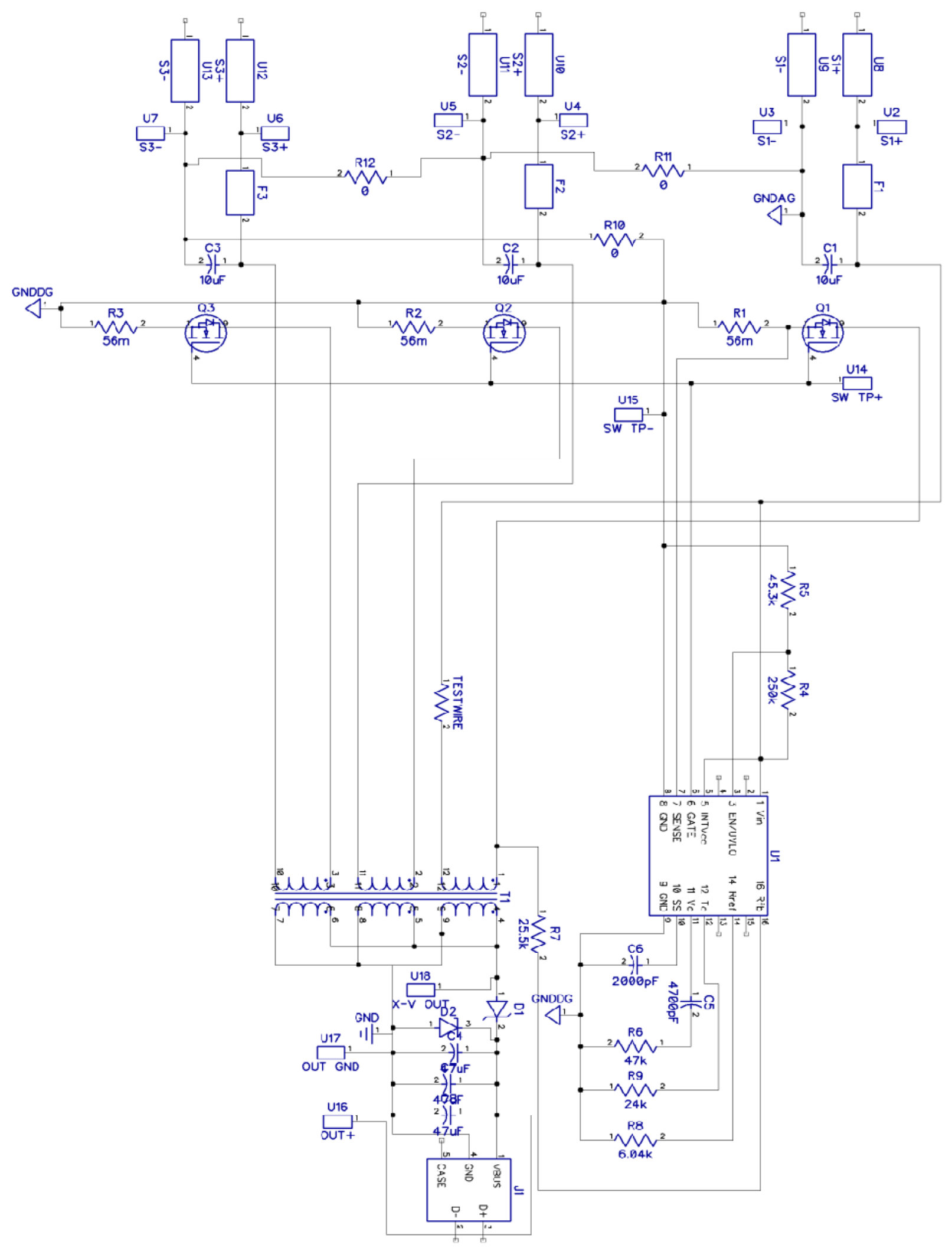

Figure 5-1: MISO Schematic Rev.1 


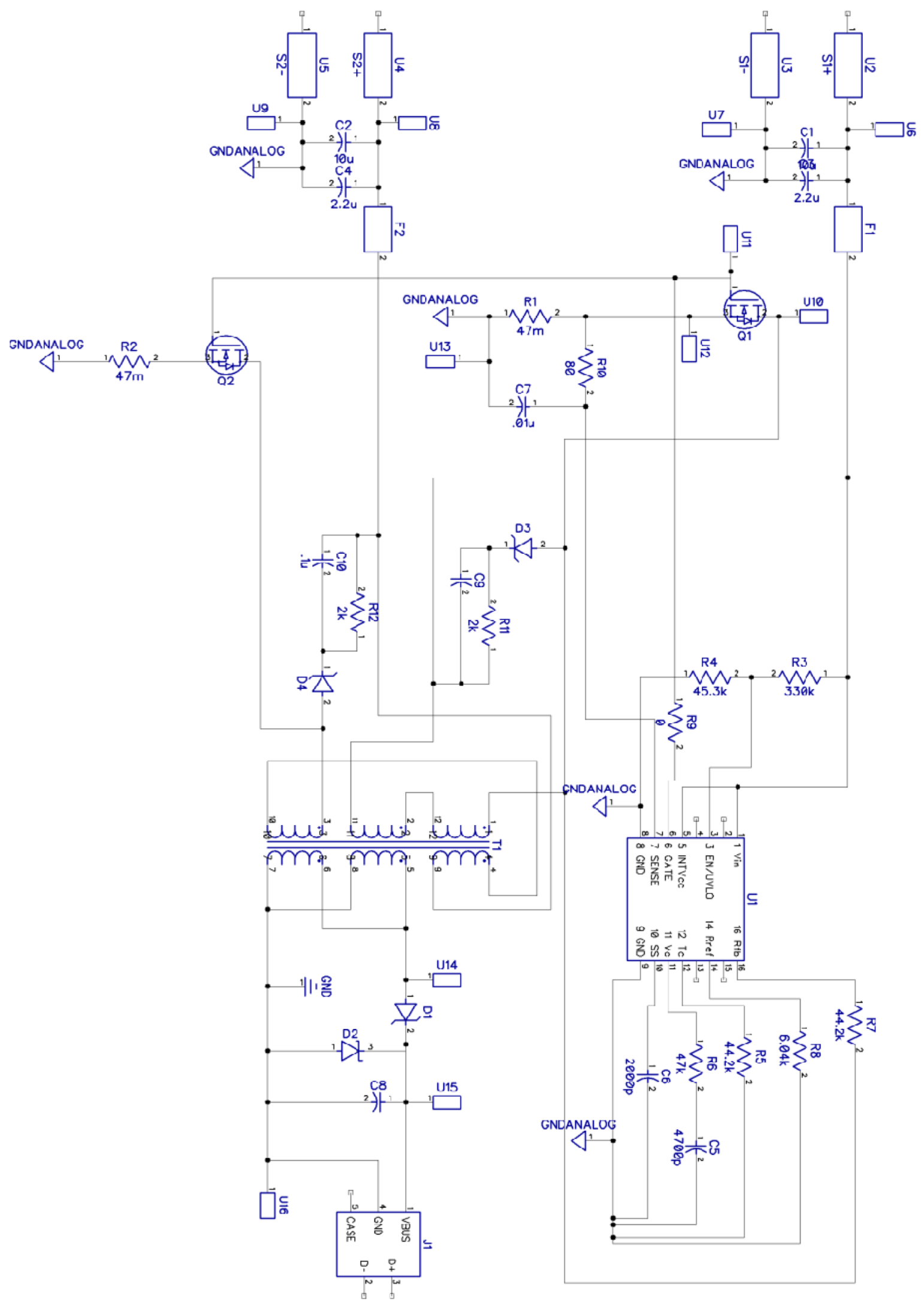

Figure 5-2: MISO Schematic Rev.2 

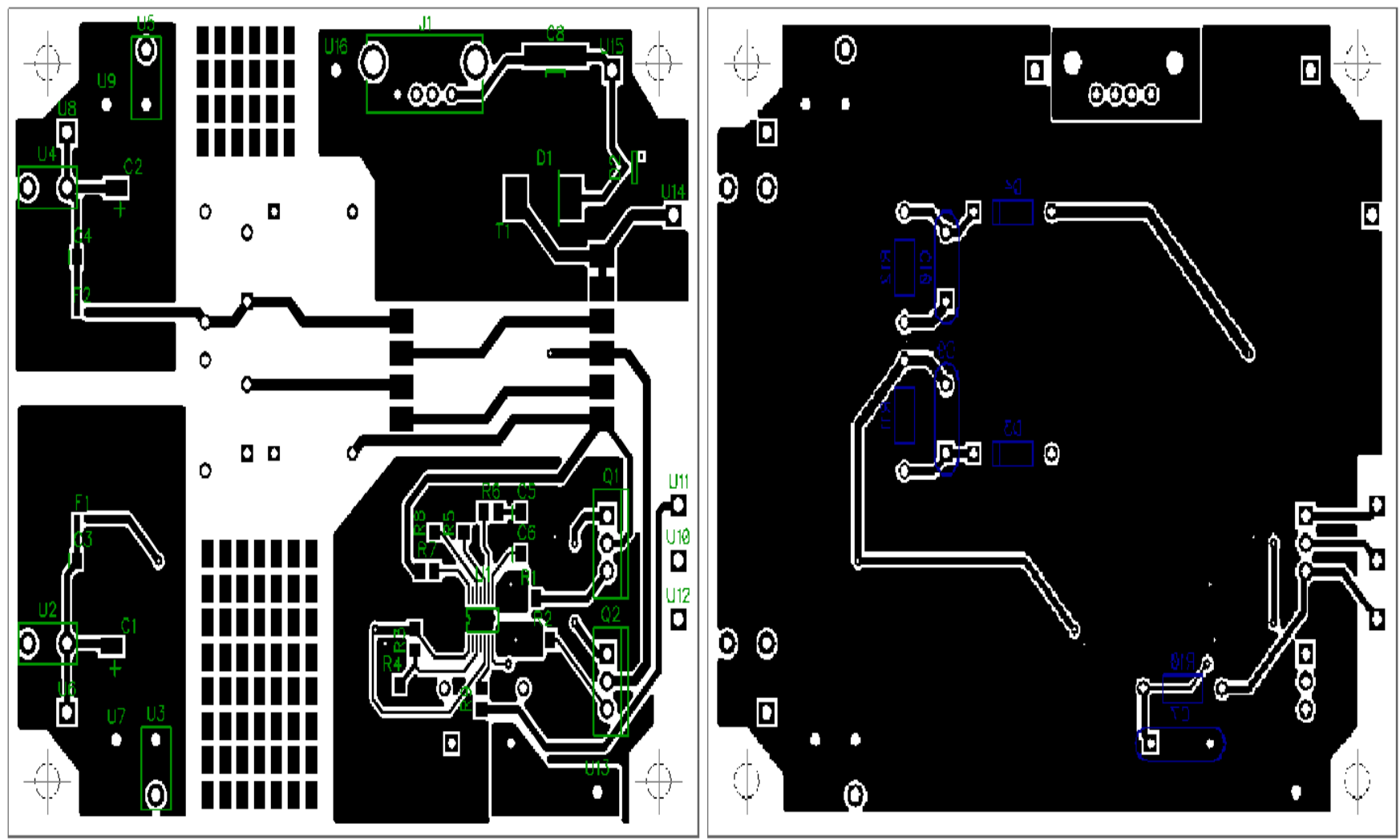

Figure 5-3: MISO PCB Layout Rev.2

Rev. 2 layout was designed with a 2:1 transformer because it was suggested that since this was this is a step down converter a step down transformer should be utilized. Due to the nature of the transformer and a 2:1 turn ratio only two sources could be utilized in the layout. However, when testing the PCB the transformer started ringing which suggested that the transformer was being saturated and was modified back to a 1:1 transformer as seen in Figure 54. It was later discovered that the ringing was cause by an additional LC filter on the sense pin. 

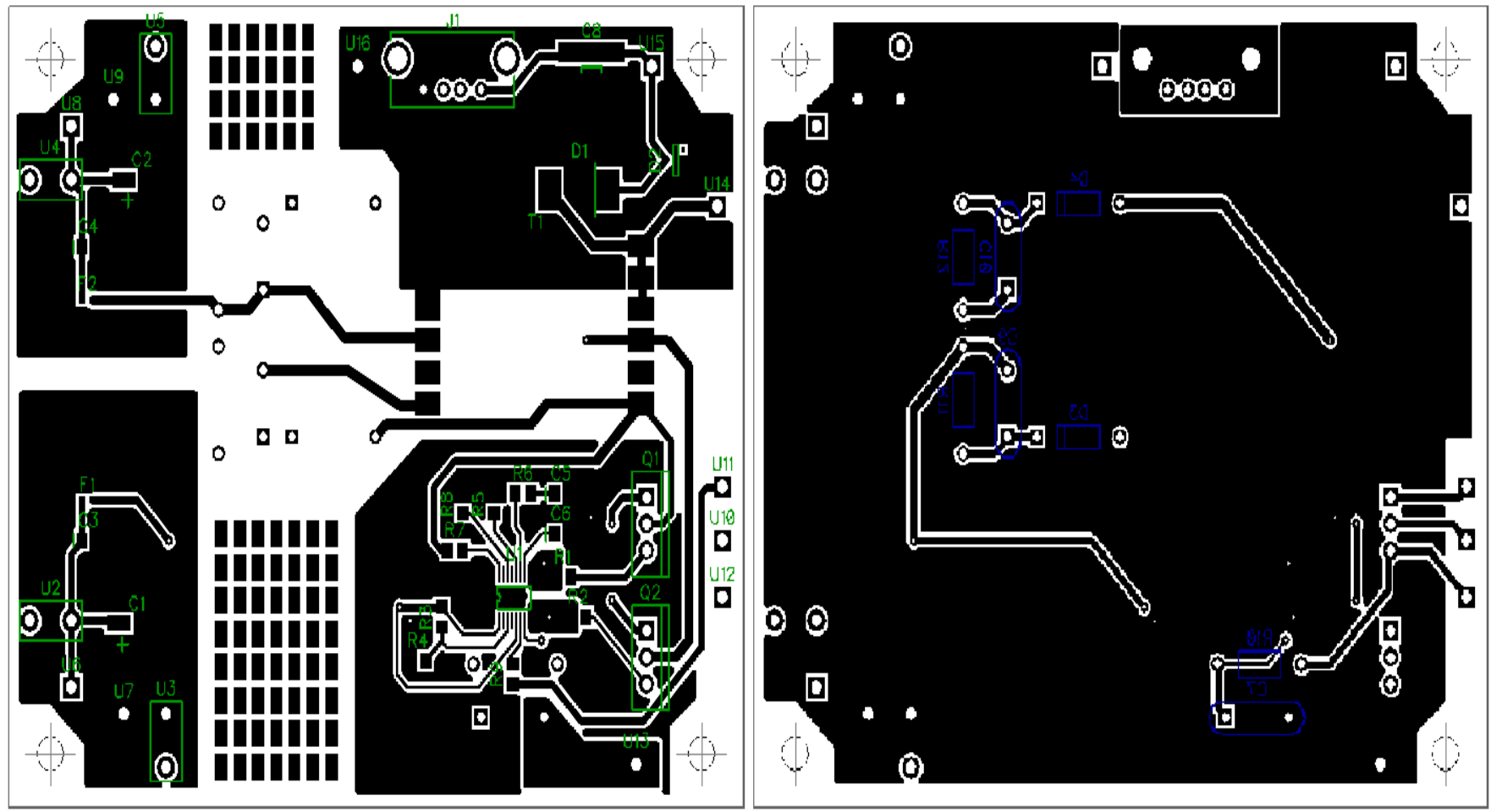

Figure 5-4: MISO PCB Layout Rev.2 Modified

When laying out the PCB it was necessary to keep in mind that $\mathrm{R}_{\mathrm{FB}}$ and $\mathrm{R}_{\mathrm{REF}}$ are needed to be physically close to the controller. Also the grounded plane connected to sense resistor needs to also be physically close to the controller and isolated to reduce noise. The layout also separated its signal ground from power ground to further suppress noise. A combination of surface mount (for sensing functions and the controller) and through-hole components (for power components) were used to ensure reliability. The LT3748 requires a minimum of $2 \%$ load $(10 \mathrm{~mA})$; otherwise the output voltage keeps rising [21]. Since the minimum load is relatively small a zener diode with a $5 \mathrm{~V}$ breakdown will be enough to act as the dummy load while helping maintain the desired 5V output. After initial testing the leakage inductance caused almost a $17 \mathrm{~V}$ voltage spike almost doubling the voltage seen by the switch. In order to remedy this, a RCD snubber circuit was place across both input windings reducing the voltage spike to $9 \mathrm{~V}$. 
Figure 5-5 shows the completed MISO Hardware where input 1, a solar and battery combination, drives the controller while delivering power to the load with input 2 , a bicycle dynamo generator. The output regulates 5 volts through a USB port.

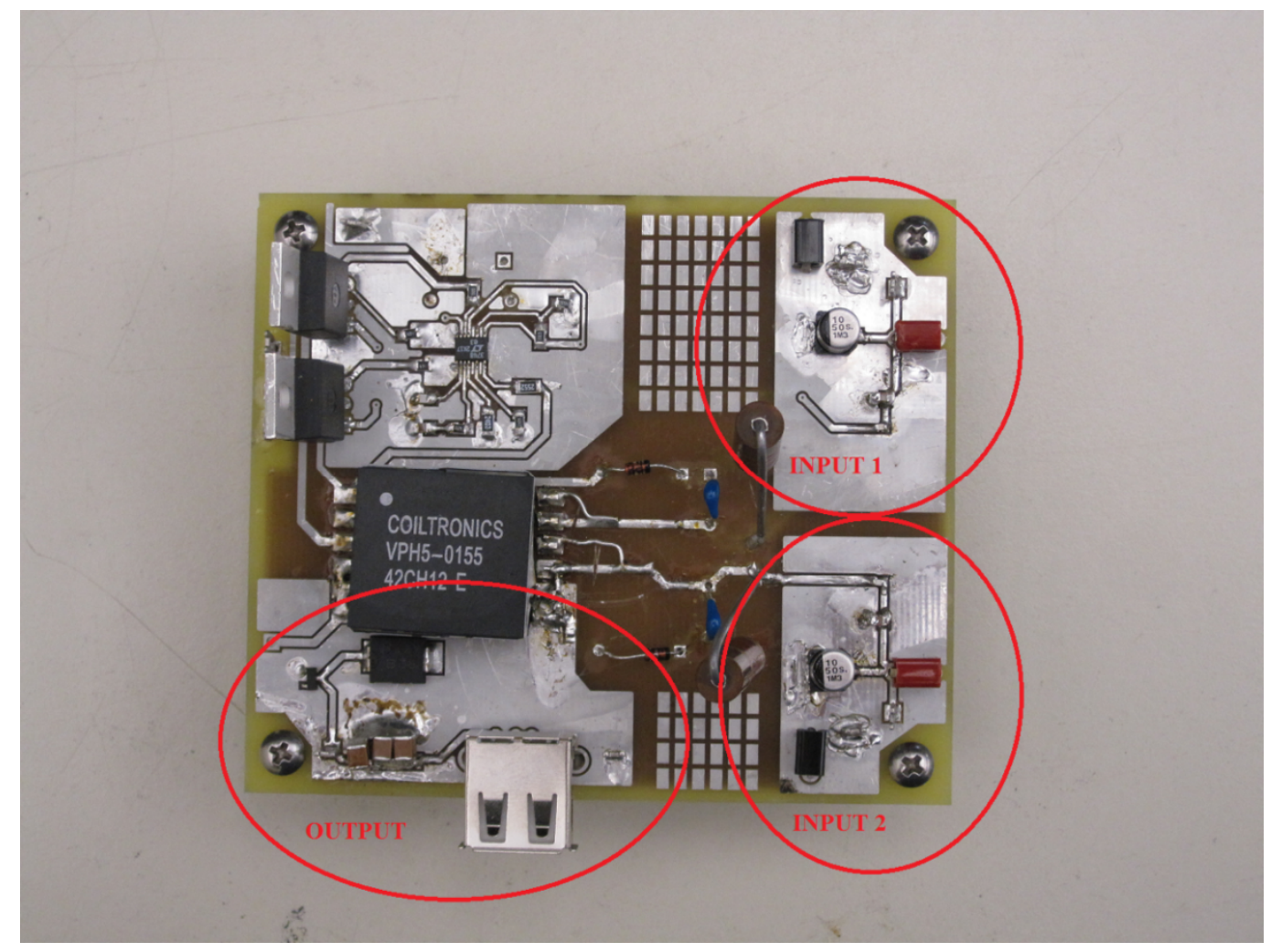

Figure 5-5: Multiple Input Single Output (MISO) Converter

A block diagram and actual setup of the converter with two DC sources can be seen in Figures 5-6 and 5-7. The two DC power supplies are meant to simulate as the renewable sources for testing purposes. The output will be connected to an electronic load drawing constant current of $0.5 \mathrm{~A}$ at $5 \mathrm{~V}$ simulating full load. The MISO converter was tested under multiple conditions where only input 1 is on and when both input 1 and input 2 are on concurrently. 


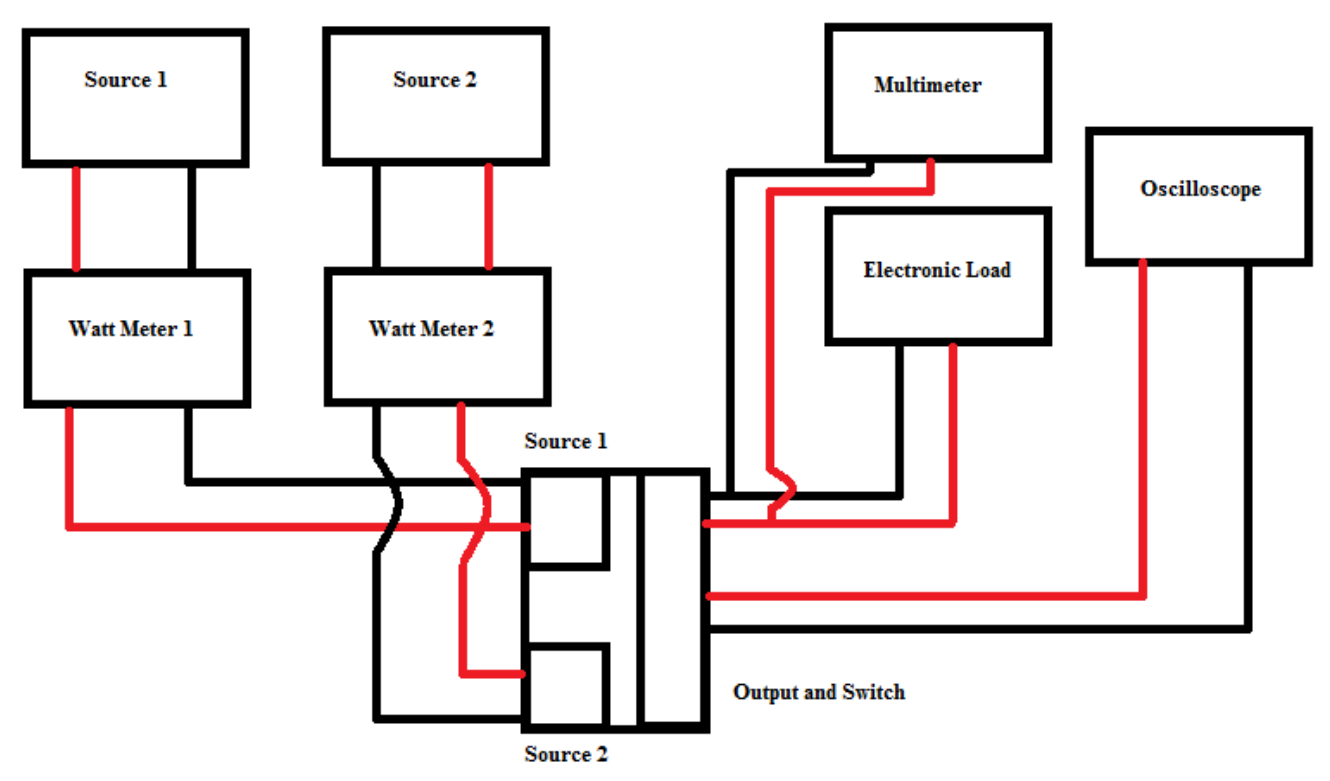

Figure 5-6: MISO Test Setup Block Diagram

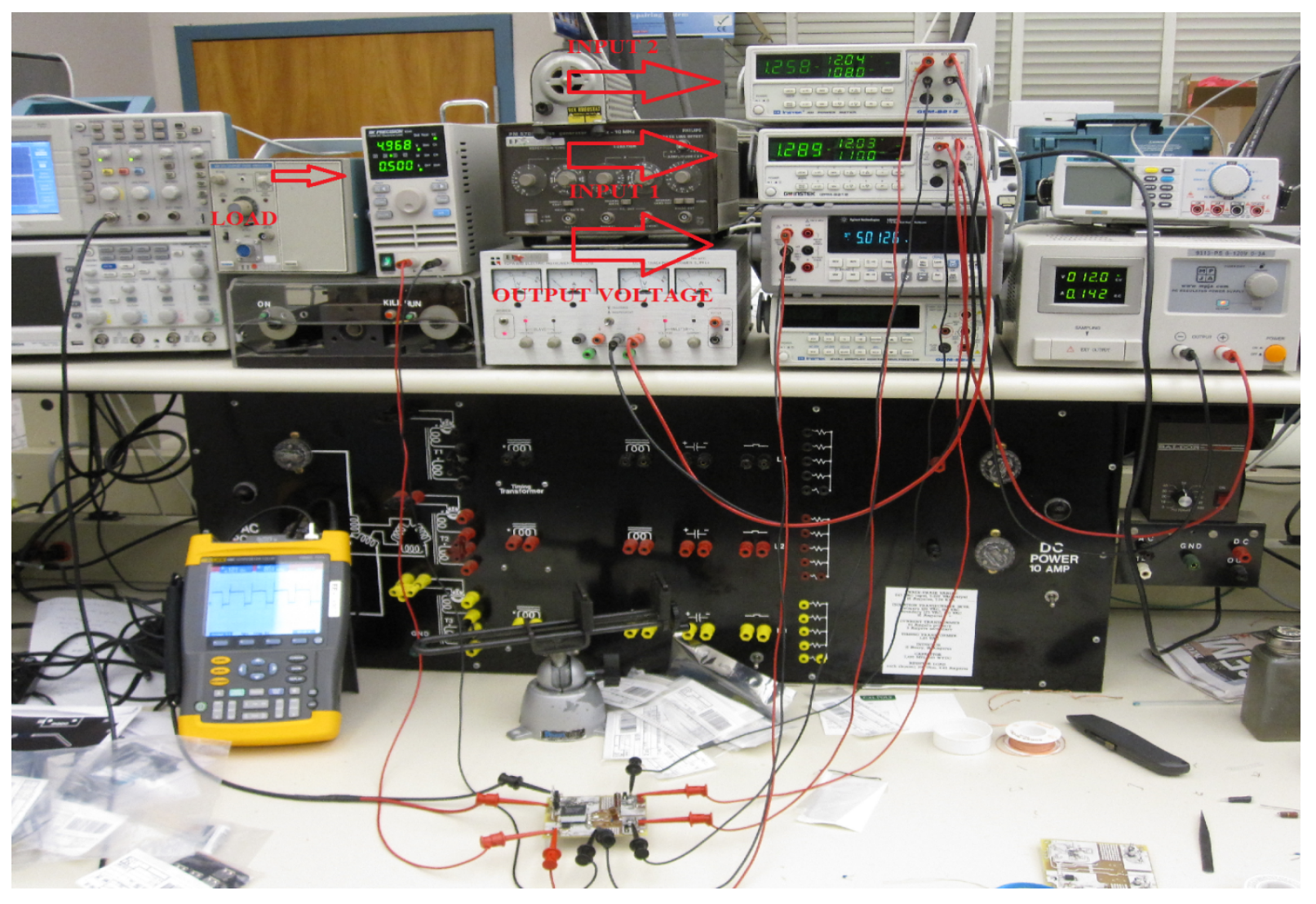

Figure 5-7: MISO Test Setup at Full Load with Two Inputs 


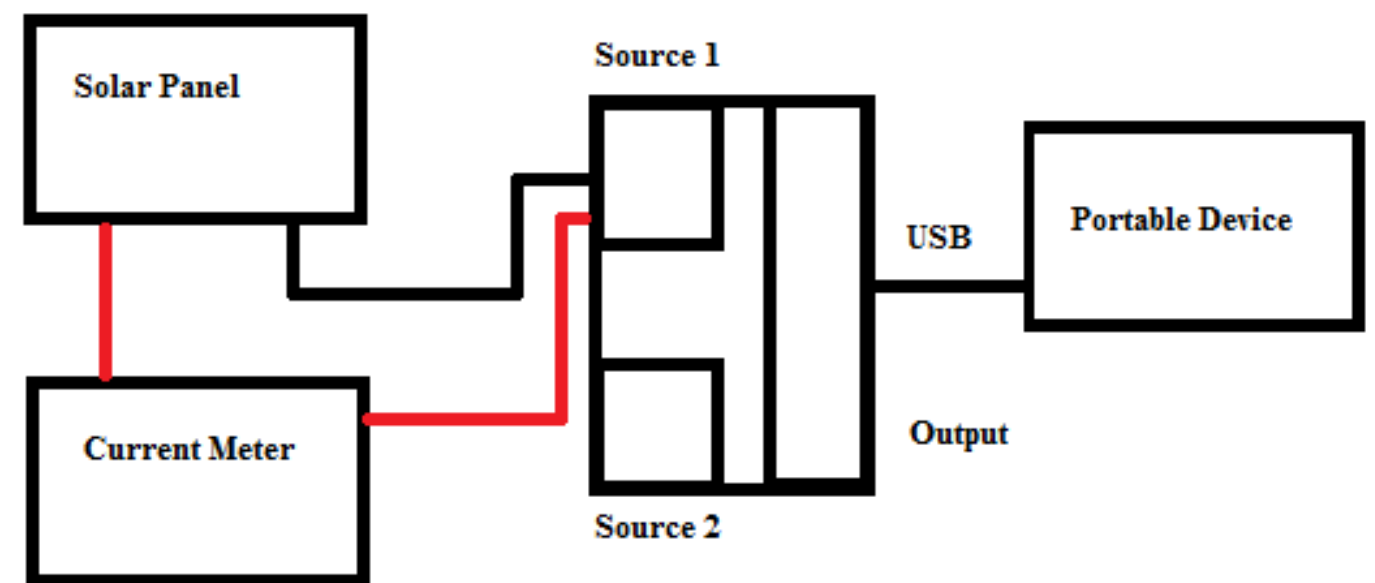

Figure 5-8: Solar Panel Test Setup Block Diagram

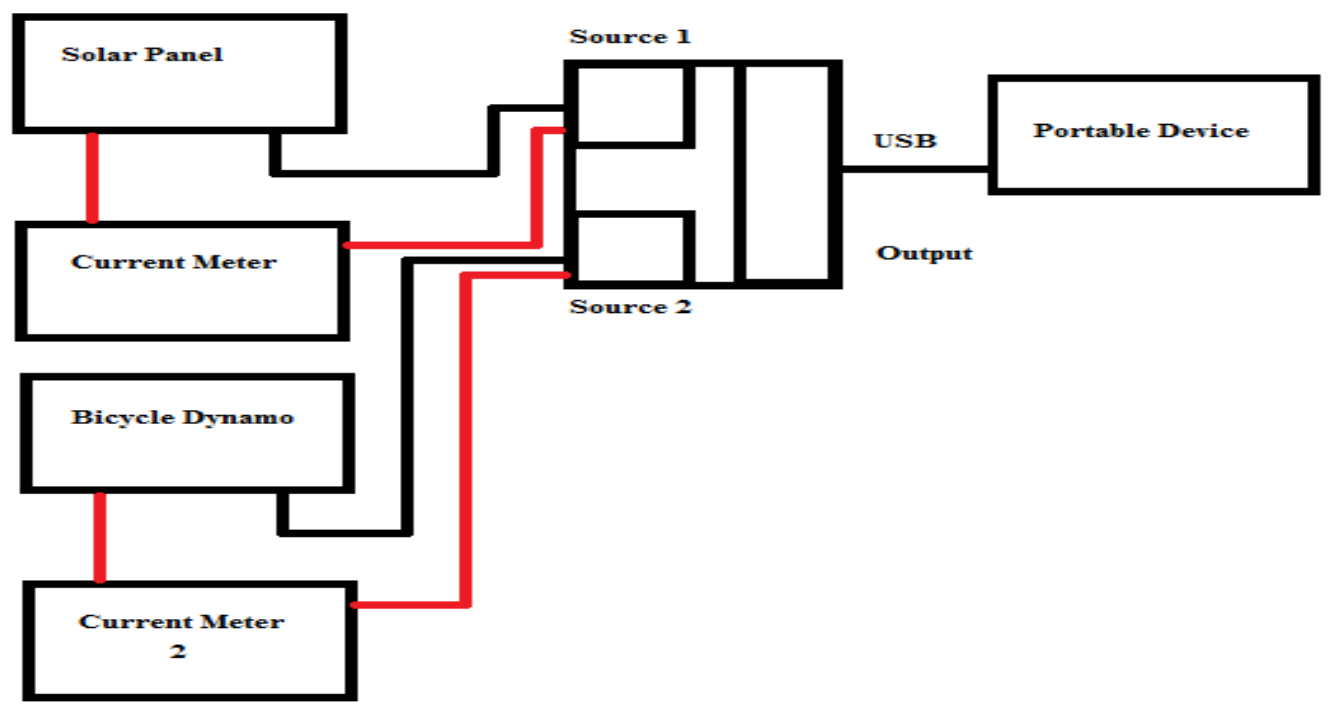

Figure 5-9: Solar Panel and Bicycle Dynamo Test Setup Block Diagram

Figures 5-8 and 5-9 show the block diagram of the actual sources being implemented. In the following Figures 5-10 and 5-11 pictures of the actual system and total amount of current that is drawn. 


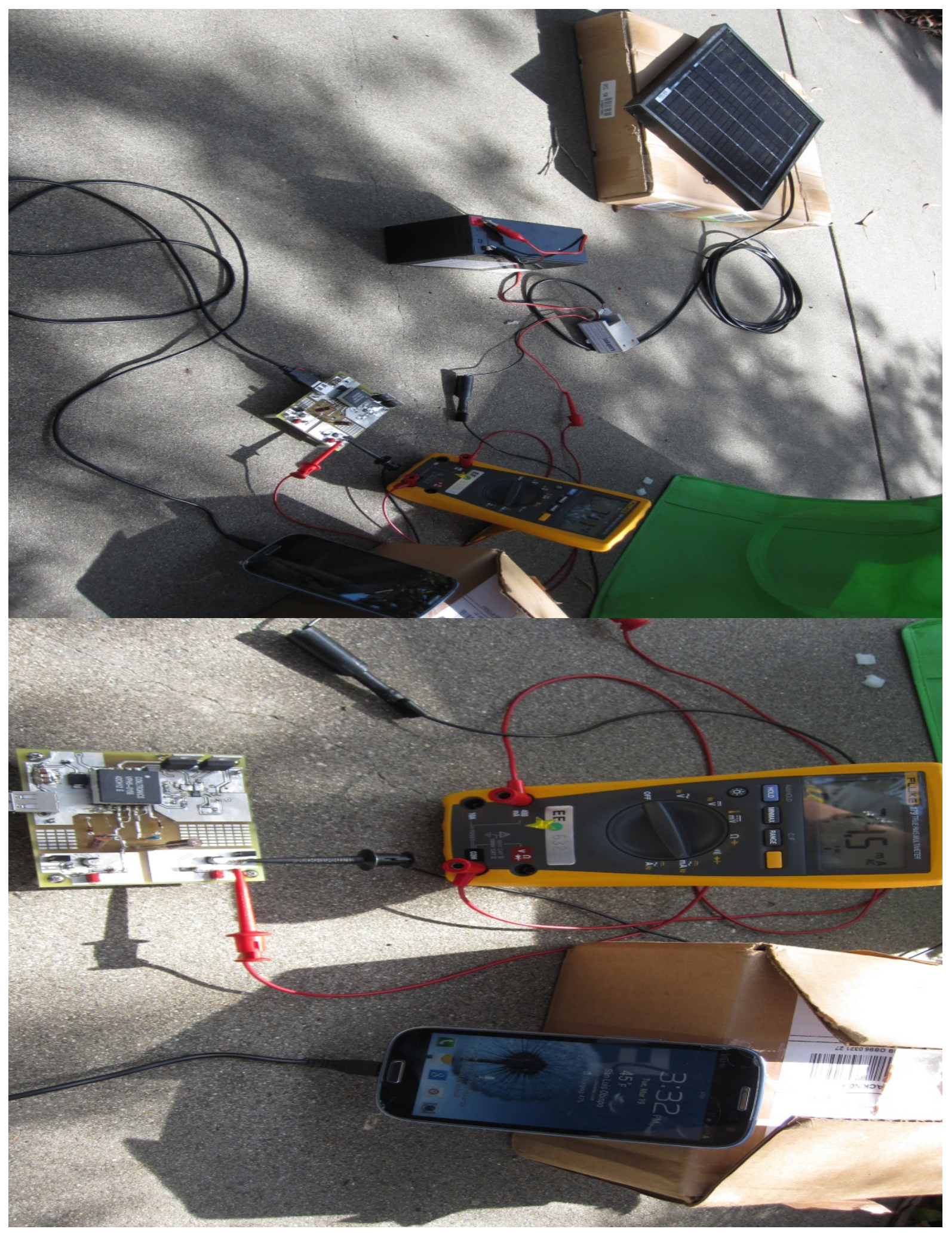

Figure 5-10: Solar Panel Charge Testing (Drawing 74.5mA) 


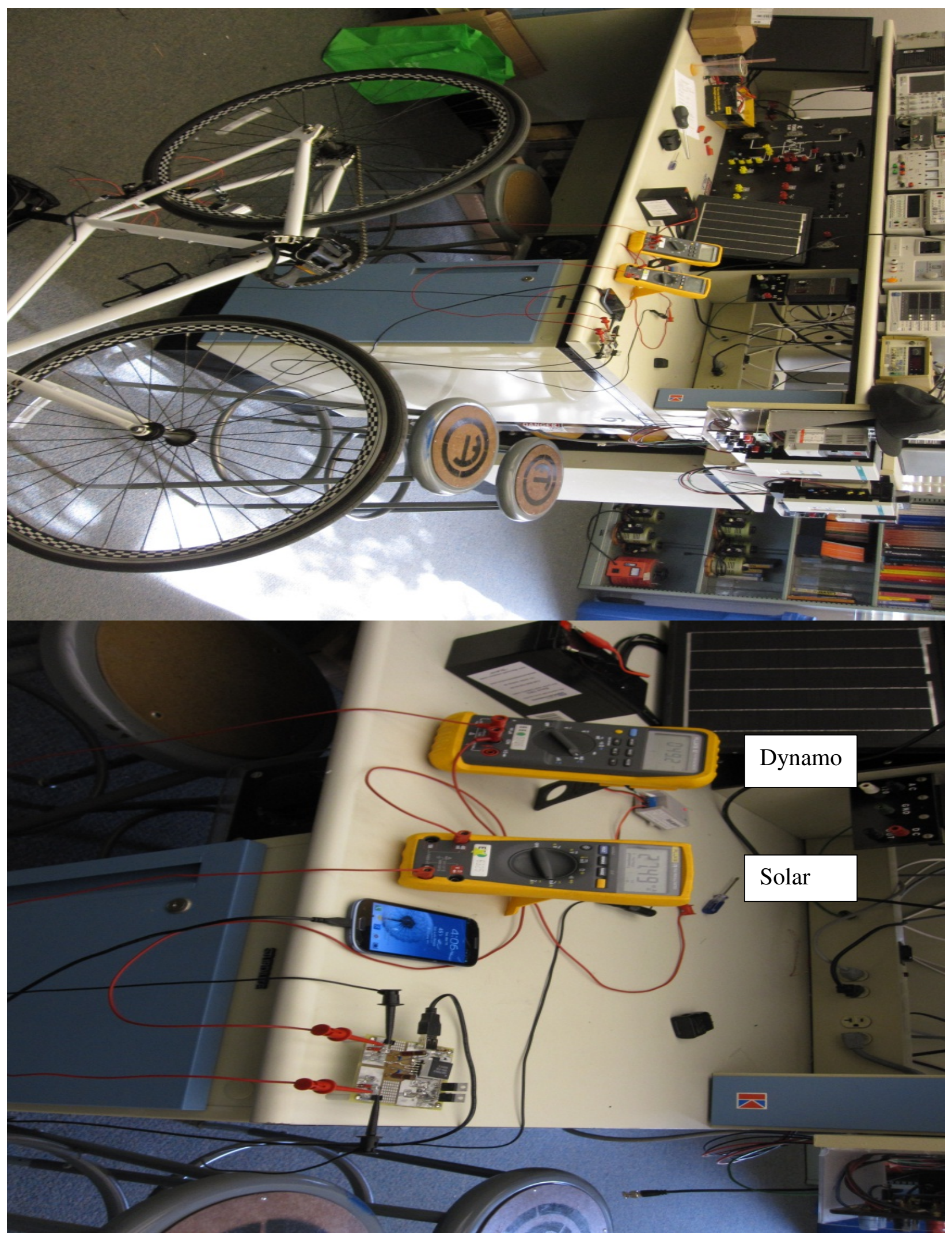

Figure 5-11: Solar Panel and Bicycle Dynamo Charge Testing (Solar Drawing 27.5mA, Dynamo Drawing 50mA) 
Finally, as seen in Figure 5-10 and 5-11 the MISO hardware was tested with the actual solar panel/ battery combo individually as well as in conjunction with the bicycle dynamo generator. It can be seen from the figures that the MISO is able to draw power from both sources simultaneously based on the current meters. From the meters only a total of about $75 \mathrm{~mA}-$ $77 \mathrm{~mA}$ were being drawn instead of the $110 \mathrm{~mA}$ and $106 \mathrm{~mA}$ as seen from the power supply testing. This is due to the fact that depending on the total charge of the lithium ion battery the current draw will drop off the more the battery is close to full charge, so as to not damage or over charge the battery.

\subsection{Results}

All data collected on input voltage, input current, efficiency, \% load regulation under these conditions are located in Tables 5-1 and 5-2. The over efficiency, $\%$ line regulation, $\%$ load regulation, and peak-to-peak ripple under full load and two input sources can be view in Table 5-3. To ensure that the converter maintains regulation and that the soft switching doesn't activate, which shut downs the controller, the sense pin is monitored to make sure that it doesn't hit its $100 \mathrm{mV}$ limit. 
Table 5-1: Efficiency and Load Regulation with One Source

\begin{tabular}{|c|c|c|c|c|c|c|}
\hline \multicolumn{7}{|c|}{ Efficiency and Load Regulation with One Source } \\
\hline $\mathrm{V}_{\text {in1 }}(\mathrm{V})$ & $\mathrm{I}_{\text {in1 }}(\mathrm{A})$ & $\mathrm{V}_{\text {out }}(\mathrm{V})$ & $\mathrm{I}_{\text {out }}(\mathrm{A})$ & $\%$ Load & Efficiency & $\%$ Load Regulation \\
\hline 12 & 0.08 & 4.98 & 0.05 & $10 \%$ & $25.94 \%$ & $0.20 \%$ \\
\hline 12 & 0.098 & 4.98 & 0.1 & $20 \%$ & $42.35 \%$ & $0.20 \%$ \\
\hline 12 & 0.127 & 4.97 & 0.2 & $40 \%$ & $65.22 \%$ & $0.00 \%$ \\
\hline 12 & 0.162 & 4.969 & 0.3 & $60 \%$ & $76.68 \%$ & $0.02 \%$ \\
\hline 12 & 0.199 & 4.968 & 0.4 & $80 \%$ & $83.22 \%$ & $0.04 \%$ \\
\hline 12 & 0.246 & 4.97 & 0.5 & $100 \%$ & $84.18 \%$ & $0.00 \%$ \\
\hline
\end{tabular}

Table 5-2: Efficiency and Load Regulation with Two Sources

\begin{tabular}{|c|c|c|c|c|c|c|c|c|}
\hline \multicolumn{8}{|c|}{ Efficiency and Load Regulation with Two Sources } \\
\hline $\mathrm{V}_{\text {in1 }}(\mathrm{V})$ & $\mathrm{I}_{\text {in1 }}(\mathrm{A})$ & $\mathrm{V}_{\text {in2 }}(\mathrm{V})$ & $\mathrm{I}_{\text {in2 }}(\mathrm{A})$ & $\mathrm{V}_{\text {out }}(\mathrm{V})$ & $\mathrm{I}_{\text {out }}(\mathrm{A})$ & $\begin{array}{c}\% \\
\text { Load }\end{array}$ & Efficiency & $\begin{array}{c}\text { \% Load } \\
\text { Regulation }\end{array}$ \\
\hline 12 & 0.03 & 12 & 0.033 & 5 & 0.05 & $10 \%$ & $33.07 \%$ & $0.08 \%$ \\
\hline 12 & 0.042 & 12 & 0.048 & 4.997 & 0.1 & $20 \%$ & $46.27 \%$ & $0.14 \%$ \\
\hline 12 & 0.062 & 12 & 0.076 & 4.995 & 0.2 & $40 \%$ & $60.33 \%$ & $0.18 \%$ \\
\hline 12 & 0.0857 & 12 & 0.0925 & 5 & 0.3 & $60 \%$ & $70.15 \%$ & $0.08 \%$ \\
\hline 12 & 0.0948 & 12 & 0.1005 & 5.001 & 0.4 & $80 \%$ & $85.36 \%$ & $0.06 \%$ \\
\hline 12 & 0.111 & 12 & 0.106 & 5.004 & 0.5 & $100 \%$ & $96.08 \%$ & $0.00 \%$ \\
\hline
\end{tabular}

The following data can be calculated from the equations below:

$$
\begin{gathered}
\text { Output Power }=P_{\text {omax }}=V_{o \text { full load }} * I_{\text {o full load }} \\
\% \text { Load Regulation }=\frac{V_{o \text { min load }}-V_{o \text { full load }}}{V_{\text {onominal }}} \\
\% \text { Line Regulation }=\frac{V_{\text {oat Vin max }}-V_{\text {oat Vin min }}}{V_{\text {onominal }}} \\
\% \text { Ripple }=\frac{V_{\text {ripple peak-to-peak }}}{V_{o}} * 100
\end{gathered}
$$

Below Figure 5-12 shows the overall efficiency vs \% load and 5-13 shows $\mathrm{P}_{\text {out MAX }}$ depending on the amount of input sources. From the data it can be seen that with an increased 
number of sources the converter is able to produce slightly more power as well as being more efficient. It can be seen that with increasing the number of sources there is an increases in the efficiency and as well as maximum output power. This is due to the fact that the current draw is now divided between the two paths. Since power is $\mathrm{P}=\mathrm{I}^{2} \mathrm{R}$ and having less current flowing through the MOSFET and snubber circuit will result in decrease power losses.

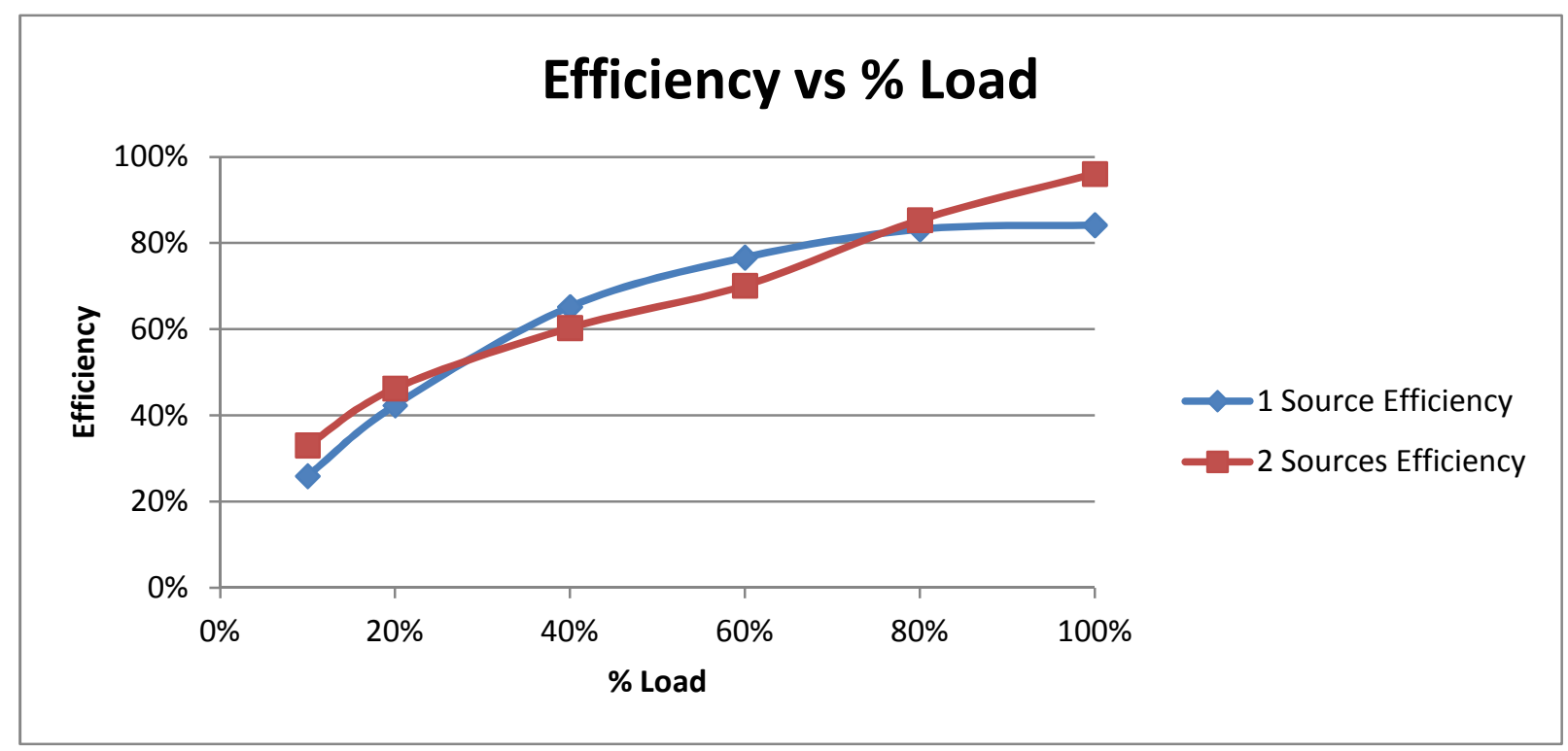

Figure 5-12: MISO Efficiency over a Varied Load 


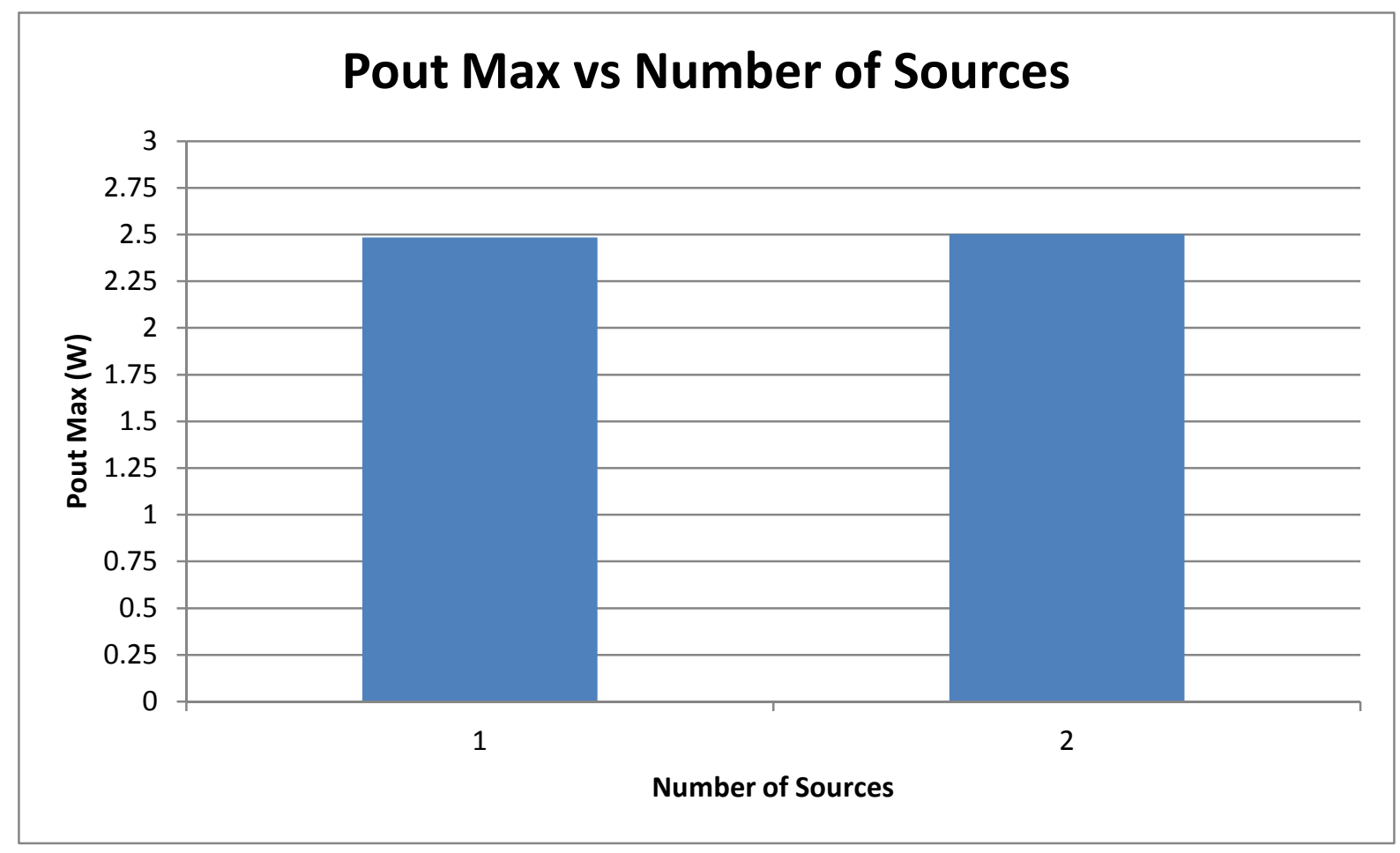

Figure 5-13: Pout Max under Multiple Source Conditions

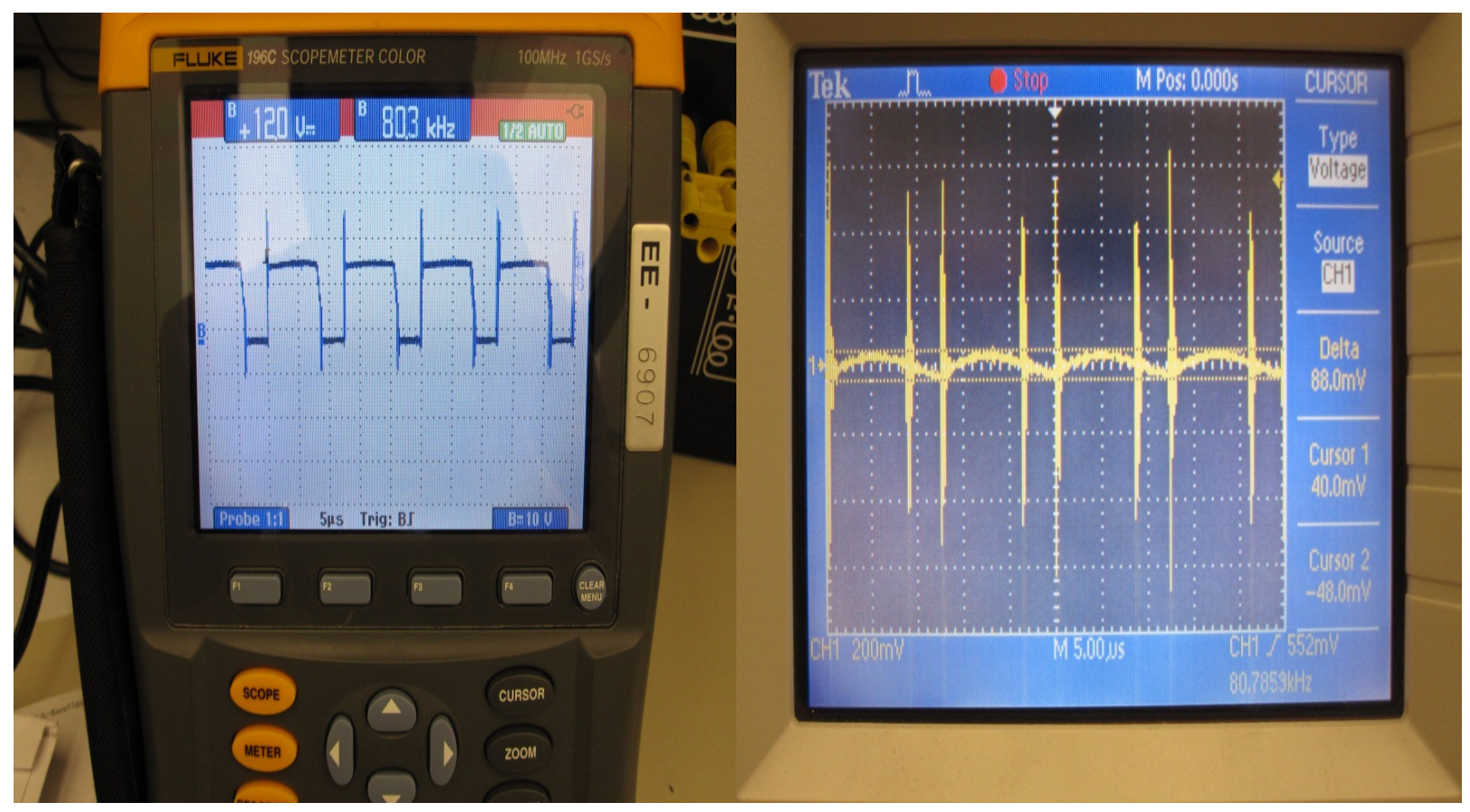

Figure 5-14: Output Peak-to-Peak Ripple at Full load with Two Sources 
From the data collected using the lab setup shown in Figure 5-6 it can be seen that the MISO converter has successfully interfaced and combined two sources to a single stable output voltage that can produce about $2.502 \mathrm{~W}$. The output ripple $(88 \mathrm{mV})$ was highest when two sources were used which was still within desired specification which can be seen in Figure 5-14.

Table 5-3 summarizes the overall performance of the converter. When comparing the overall data to the calculations and simulations the actual values were quite similar. However, the overall efficiency with both sources on was much greater than the predicted LTSpice efficiency report. Also, it was found out that the actual switching frequency was about $80 \mathrm{kHz}$ instead of the calculated $98.6 \mathrm{kHz}$ or simulated $92.5 \mathrm{kHz}$. However, the calculation was just an estimate and having the actual switching frequency lower helps with switching losses explaining why the efficiency is actually higher than in the simulation.

Table 5-3: Performance at Max Load with Two Sources

\begin{tabular}{|c|c|}
\hline \multicolumn{2}{|c|}{ Overall Performance } \\
\hline $\mathrm{I}_{\text {out }}$ Max & $0.5 \mathrm{~A}$ \\
\hline $\mathrm{V}_{\text {out }}$ at Max Load & $4.963 \mathrm{~V}$ \\
\hline Output Power & $2.48 \mathrm{~W}$ \\
\hline \% Load Regulation $(.05 \mathrm{~A}-.5 \mathrm{~A})$ & $0.08 \%$ \\
\hline \% Line Regulation $(11 \mathrm{~V}-14 \mathrm{~V})$ & $0.14 \%$ \\
\hline \% Efficiency & $96.08 \%$ \\
\hline Output Voltage Ripple & $88 \mathrm{mV}$ \\
\hline
\end{tabular}

The hardware test set up as seen in Figure 5-7 showed that the MISO converter meets the desired requirements in chapter 3 . The MISO was able to fully combine two different renewable sources while charging the Samsung Galaxy 3S. Even though the actual hardware was only able to combine two sources instead of the required three due to unforeseen layout problem, this 
MISO was still a success. If funds were available another revision to the PCB schematic could be done to add the additional input source. Still as a proof of concept this MISO demonstrated that it is possible to utilize all off the shelf components and construct a converter that takes in various renewable energies to charge a portable device through USB power. 


\section{Conclusion and Improvements}

This thesis project proposed the design and implementation of a Multiple Input Single Output (MISO) converter with a USB output to charge portable electronics such as cell-phones, tablet, etc. The MISO converter is designed to be compact, using only off-the-shelf components, so that it can be easily reproduced by anyone at a low cost. The MISO converter is also designed to be low power while maintaining a relatively high overall efficiency. Two input sources (Solar Panel/ Battery combination and Bicycle Dynamo) were implemented and tested using the proposed MISO instead of the three input sources that were originally planned. This was due mainly to unforeseen PCB layout designs errors. However, this converter still demonstrates a success in proving that it is possible to combine multiple sources with the currently available components to charge portable electronics. Revision 2 mod design will actually allow for third input to be added since an extra winding is available. By altering the PCB layout to add another input terminal, MOSFET, sense resistor, and snubber circuit, a third source could be easily implemented as long as the ground plane of this sense resistor is close to the controller and isolated along with the other two sense resistors.

This MISO converter using the flyback topology has satisfied the design requirements and successfully demonstrates a proof of concept of MISO technique for use with multiple sources and one output at low power. However, some modifications to improve the converter could be implemented. When testing with the actual solar panel and bicycle dynamo it was found that the converter would stop charging the phone if input 1 was already on and then input 2 was attached but not running. This was due to the transformer delivering the load to input 2 instead of the output. This can be fixed by implementing PN-junction diode like solar panel arrays. By 
implementing a PN-junction diode at the input of each source after the fuse it will act like a blocker only allowing current to flow one direction preventing sources from drawing current from each other. By implementing the diode on the converter itself it becomes unnecessary to worry about if the renewable sources are unidirectional and if they would draw current from the other inputs.

Due to the limitation of the currently available transformers it becomes difficult to reduce leakage inductance. If this was custom part a sandwich pattern and bifilar winding technique could be implemented to help reduce the leakage inductance and possibly increase efficiency of the transformer. Even though a RCD snubber circuit was implemented to reduce the leakage spike at the tradeoff of more power loss, the RCD circuitry was not yet optimized. Additional capacitance in parallel could help reduce the leakage spike at the cost of more power loss. During testing, the snubber capacitance was increased to $.3 \mu \mathrm{F}$, but was not able to find the optimal capacitance to reduce the leakage spike as much as possible due to limited capacitors available at the time of testing. Further testing with different capacitance values from . $1 \mu \mathrm{F}$ $.3 \mu \mathrm{F}$ would be ideal to remedy this.

Overall, the converter is small in size, 3' $\mathrm{X} 3.5^{\prime}$ ', great for portability, but there is a lot wasted space and could be further reduced especially given the low number of parts required. The MISO was also able to achieve isolation from the primary to secondary side required in order to protect the device that is being charged. Thanks to the primary side current sensing, the MISO was able to attain information about the secondary side while maintaining isolation, 
reducing cost and board space. This would not be the case should a tertiary winding or optoisolator be implemented.

From the cost analysis, the entire system with two sources costs a total of $\$ 159.18$. The converter itself is relatively inexpensive and cost could be further reduced if it was mass produced. The main cost comes from the renewable sources. Most solar panel small in size actually costs more dollar/ watt than larger ones because of the lack of demand for smaller solar panels. However, due to the converters versatility, as long as the input is a constant $12 \mathrm{~V}$ and can produce at least $4 \mathrm{~W}$ then any renewable source can be used, making the converter adaptable for any area where any renewable source is available.

In conclusion, this thesis demonstrates the capability of the MISO converter to take in multiple renewable sources and convert them into a single regulated, useable USB output to charge portable electronics such as tablets or smartphones. The MISO converter is a success and meets the requirements of being small, efficient, and easily reproducible. 


\section{References}

[1] Y. M. Chen, Y. C. Liu, and F. Y. Wu. (2002). "Multi-Input DC/DC Converter Based on the Multiwinding Transformer for Renewable Energy Applications." [Internet] Available: http://ieeexplore.ieee.org/stamp/stamp.jsp?arnumber=01019967

[2] Wong, Taffy Chi Kin. (October 2011). “A Multiple-Input Single-Output DC-DC Converter For The DC House Project." [Internet] Available: http://digitalcommons.calpoly.edu/cgi/viewcontent.cgi?article $=1669 \&$ context $=$ theses

[3] Jong, Owen. (June 2012). "Multiple Input Single Output (MISO) DC-DC Converter for the DC House Project." [Internet] Available: http://digitalcommons.calpoly.edu/cgi/viewcontent.cgi?article=1164\&context=eesp

[4] Unknown. (2013). “developing country.” [Internet] Available: http://dictionary.reference.com/browse/developing+country

[5] The Economist. (September 2, 2010). "Energy in the Developing World: Power to the People." [Internet] Available: http://www.economist.com/node/16909923

[6] Bullis, Kevin. (January 27, 2012). "In the Developing World, Solar is Cheaper than Fossil Fuels.” [Internet] Available: http://www.technologyreview.com/news/426718/in-thedeveloping-world-solar-is-cheaper-than-fossil-fuels/?p1=MstCom

[7] Graps, Amara. (July 2008). “The Sun-Earth Connection.” [Internet] Available: http://solarcenter.stanford.edu/sun-on-earth/sun-earth.html

[8] Knier, Gil. “How Do Photovoltaics Work?” [Internet] Available: http://science.nasa.gov/science-news/science-at-nasa/2002/solarcells/

[9] Etap. "Solar Panel Diagram." [Internet] Available: http://etap.com/renewableenergy/photovoltaic-101.htm

[10] Thompson, Silvanus P. (1886). “Dynamo-electric Machinery.” Page 4, 7. [Internet] Available: http://books.google.com/books?id=$\underline{\text { RVDAAAAIAAJ\&pg }=\text { PA } 1 \& \text { source }=g b s \_t o c \_r \& c a d=4 \# v=\text { onepage } \& q \& \mathrm{f}=\text { false }}$

[11] Unknown. "Bicycle Dynamo." [Internet] Available: http://books.google.com/books?id=$\underline{\text { RVDAAAAIAAJ\&pg }=\text { PA } 1 \& \text { source }=g b s \_t o c \_r \& c a d=4 \# v=\text { onepage } \& q \& \mathrm{f}=\text { false }}$

[12] Hartman, Liz. (August 14, 2012). “Top 10 Things You Didn’t Know About Wind.” [Internet] Available: http://energy.gov/articles/top-10-things-you-didnt-know-about-wind 
[13] Unknown. (January 17, 2013). "How Do Wind Turbines Work?” [Internet] Available: http://www1.eere.energy.gov/wind/printable_versions/wind_how.html

[14] Unknown. (January 17, 2013). “The Inside of a Wind Turbine.” [Internet] Available: http://www1.eere.energy.gov/wind/printable_versions/inside_a_wind_turbine.html

[15] Unknown. (October, 11, 2011). "How Hydropower Works.” [Internet] Available: http://www1.eere.energy.gov/water/how_hydropower_works.html

[16] Perlman, Howard. (January 7,2013). "Hydroelectric Power: How it Works." [Internet] Available: http://ga.water.usgs.gov/edu/hyhowworks.html

[17] Texas Instruments. (2010). "Under the Hood of Flyback SMPS Design.” [Internet] Available: http://www.ti.com/lit/ml/slup261/slup261.pdf

[18] Sclocchi, Michele. (October 25, 2011). "Step by Step for an Optimized Flyback Design." [Internet] Available: http://www.power-eetimes.com/en/step-by-step-for-an-optimisedflyback-design.html?cmp_id=71\&news_id=222903558

[19] USB Implementers Form Inc. (December 7, 2010). "Battery Charging Specification Rev 1.2." [Internet] Available: http://www.usb.org/developers/devclass_docs

[20] Kollman, Robert and Betten, John. "Powering Electronics From the USB Port." [Internet] Available: http://www.ti.com/lit/an/slyt118/slyt118.pdf

[21] Linear Technology. "LT3748 100V Isolated Flyback Controller.” [Internet] Available: http://cds.linear.com/docs/en/datasheet/3748fa.pdf

[22] Cooper Bussmann. "VERSA-PAC Inductors and Transformers (Surface Mount)." [Internet] Available:

http://www.cooperindustries.com/content/dam/public/bussmann/Electronics/Resources/Data \%20Sheets/Bus_Elx_DS_PM\%204301_VERSA-PAC(VP1_2_3_4_5_VPH1_2_3_4_5).pdf 


\section{Appendix A: Bill of Materials}

\begin{tabular}{|c|c|c|c|c|c|}
\hline \multicolumn{6}{|c|}{ Total Cost on MISO Converter } \\
\hline Index & Quantity & Part Number & Description & $\begin{array}{l}\text { Unit } \\
\text { Price }\end{array}$ & $\begin{array}{c}\text { Extended } \\
\text { Price }\end{array}$ \\
\hline 1 & 6 & 1175-1015-ND & $\begin{array}{l}\text { CONN USB A TYPE R/A } \\
\text { THROUGH HOLE }\end{array}$ & 0.6900 & $\$ 4.14$ \\
\hline 2 & 20 & 1040K-ND & $\begin{array}{l}\text { TERM TEST POINT } \\
\text { SLOTTED .118" }\end{array}$ & 0.1770 & $\$ 3.54$ \\
\hline 3 & 12 & $3481 \mathrm{~K}-\mathrm{ND}$ & $\begin{array}{l}\text { STANDOFF RD 4- } \\
\text { 40THR .750"L ALUM }\end{array}$ & 0.4230 & $\$ 5.08$ \\
\hline 4 & 12 & 335-1082-ND & $\begin{array}{l}\text { MACHINE SCREW PAN } \\
\text { PHILLIPS 4-40 }\end{array}$ & 0.5400 & $\$ 6.48$ \\
\hline 5 & 10 & 445-3464-1-ND & $\begin{array}{c}\text { CAP CER 2.2UF 50V Y5V } \\
0805\end{array}$ & 0.1240 & $\$ 1.24$ \\
\hline 6 & 10 & PCE3915CT-ND & $\begin{array}{c}\text { CAP ALUM 10UF 50V 20\% } \\
\text { SMD }\end{array}$ & 0.4300 & $\$ 4.30$ \\
\hline 7 & 10 & $\begin{array}{l}\text { 0603SFF100F/32CT- } \\
\text { ND }\end{array}$ & $\begin{array}{l}\text { FUSE 1.0A 32V FAST SMD } \\
0603\end{array}$ & 0.3160 & $\$ 3.16$ \\
\hline 8 & 6 & 513-1774-ND & $\begin{array}{l}\text { INDUCTOR/TRANSFORMER } \\
\text { 22.3UH SMD }\end{array}$ & 7.6000 & $\$ 45.60$ \\
\hline 9 & 10 & IPP147N12N3 G-ND & $\begin{array}{l}\text { MOSFET N-CH } 120 \mathrm{~V} 56 \mathrm{~A} \\
\text { TO220-3 }\end{array}$ & 1.6210 & $\$ 16.21$ \\
\hline 10 & 10 & P47LLXT-ND & RES .047 OHM 1/4W 1\% 0805 & 0.7000 & $\$ 7.00$ \\
\hline 11 & 10 & WSLA-.04CT-ND & $\begin{array}{c}\text { RES .04 OHM 1/8W 1\% } 0805 \\
\text { SMD }\end{array}$ & 0.9000 & $\$ 9.00$ \\
\hline 12 & 50 & P330KCCT-ND & $\begin{array}{l}\text { RES 330K OHM 1/8W 1\% } \\
0805\end{array}$ & 0.0276 & $\$ 1.38$ \\
\hline 13 & 50 & P45.3KCCT-ND & $\begin{array}{c}\text { RES 45.3K OHM 1/8W } 1 \% \\
0805\end{array}$ & 0.0276 & $\$ 1.38$ \\
\hline 14 & 10 & P24.0KFCT-ND & $\begin{array}{c}\text { RES 24.0K OHM } 1 / 4 \mathrm{~W} 1 \% \\
1206 \mathrm{SMD}\end{array}$ & $\$ 0.10$ & $\$ 1.00$ \\
\hline 15 & 10 & P25.5KFCT-ND & $\begin{array}{c}\text { RES 25.5K OHM 1/4W } 1 \% \\
1206 \text { SMD }\end{array}$ & $\$ 0.10$ & $\$ 1.00$ \\
\hline 16 & 10 & 445-6943-1-ND & $\begin{array}{c}\text { CAP CER 4700PF 50V 5\%NP0 } \\
0805\end{array}$ & 0.1650 & $\$ 1.65$ \\
\hline 17 & 50 & P47KACT-ND & $\begin{array}{c}\text { RES 47K OHM 1/8W 5\% } 0805 \\
\text { SMD }\end{array}$ & $\$ 0.02$ & $\$ 0.81$ \\
\hline 18 & 50 & P6.04KCCT-ND & $\begin{array}{c}\text { RES } 6.04 \mathrm{~K} \text { OHM } 1 / 8 \mathrm{~W} 1 \% \\
0805 \mathrm{SMD}\end{array}$ & $\$ 0.0276$ & $\$ 1.38$ \\
\hline
\end{tabular}




\begin{tabular}{|c|c|c|c|c|c|}
\hline 19 & 50 & P0.0ACT-ND & $\begin{array}{l}\text { RES 0.0 OHM 1/8W } 0805 \\
\text { SMD }\end{array}$ & $\$ 0.0172$ & $\$ 0.86$ \\
\hline 20 & 10 & CMF80.0FCCT-ND & $\begin{array}{c}\text { RES } 80.0 \text { OHM } 1 \mathrm{~W} .1 \% \\
\text { AXIAL }\end{array}$ & 0.848 & $\$ 8.48$ \\
\hline 21 & 10 & 1460PH-ND & $\begin{array}{l}\text { CAP CER 10000PF 500V 10\% } \\
\text { RADIAL }\end{array}$ & 0.303 & $\$ 3.03$ \\
\hline 22 & 10 & 399-9186-1-ND & $\begin{array}{l}\text { CAP CER 2000PF 25V 5\% } \\
\text { NP0 0805 }\end{array}$ & $\$ 0.50$ & $\$ 5.00$ \\
\hline 23 & 6 & $\begin{array}{l}\text { MBRS360T3GOSCT- } \\
\text { ND } \\
\end{array}$ & $\begin{array}{c}\text { DIODE SCHOTTKY 60V 4A } \\
\text { SMC }\end{array}$ & $\$ 0.59$ & $\$ 3.54$ \\
\hline 24 & 8 & 568-6471-1-ND & $\begin{array}{c}\text { DIODE ZENER 5V 250MW } \\
\text { TO236AB }\end{array}$ & $\$ 0.45$ & $\$ 3.60$ \\
\hline 25 & 10 & 445-1409-1-ND & $\begin{array}{c}\text { CAP CER 47UF 10V Y5V } \\
1210\end{array}$ & $\$ 0.45$ & $\$ 4.50$ \\
\hline 26 & 10 & 445-7918-1ND & $\begin{array}{l}\text { CAP CER 10UF 20\% X5R } \\
1210 \\
\end{array}$ & $\$ 0.795$ & $\$ 7.95$ \\
\hline 27 & 10 & 568-7918-1-ND & $\begin{array}{l}\text { DIODE SMALL SIG 100V } \\
\text { 200MA ALF2 }\end{array}$ & $\$ 0.081$ & $\$ 0.81$ \\
\hline 28 & 10 & 2.00KXBK-ND & $\begin{array}{c}\text { RES } 2.00 \mathrm{~K} \text { OHM } 1 / 4 \mathrm{~W} 1 \% \\
\text { METAL FILM }\end{array}$ & $\$ 0.082$ & $\$ 0.82$ \\
\hline 29 & 10 & 445-8431-ND & $\begin{array}{l}\text { CAP CER 0.1UF 100V } 10 \% \\
\text { RADIAL }\end{array}$ & $\$ 0.333$ & $\$ 3.33$ \\
\hline 30 & 5 & ---------------- & Custom PCB & $\$ 20.20$ & $\$ 101.00$ \\
\hline 31 & 4 & ------------- & LT3748 & $\$ 0.00$ & $\$ 0.00$ \\
\hline & & & & Total & $\$ 257.27$ \\
\hline
\end{tabular}




\begin{tabular}{|c|c|c|c|c|c|}
\hline \multicolumn{6}{|c|}{ Cost to Make One Board } \\
\hline Index & Quantity & Part Number & Description & $\begin{array}{l}\text { Unit } \\
\text { Price } \\
\end{array}$ & $\begin{array}{c}\text { Extended } \\
\text { Price }\end{array}$ \\
\hline 1 & 1 & 1175-1015-ND & $\begin{array}{l}\text { CONN USB A TYPE R/A } \\
\text { THROUGH HOLE }\end{array}$ & 0.6900 & $\$ 0.6900$ \\
\hline 2 & 10 & 1040K-ND & $\begin{array}{l}\text { TERM TEST POINT } \\
\text { SLOTTED .118" }\end{array}$ & 0.1770 & $\$ 1.7700$ \\
\hline 3 & 4 & 3481K-ND & $\begin{array}{l}\text { STANDOFF RD 4- } \\
\text { 40THR .750"L ALUM }\end{array}$ & 0.4230 & $\$ 1.6920$ \\
\hline 4 & 4 & 335-1082-ND & $\begin{array}{l}\text { MACHINE SCREW PAN } \\
\text { PHILLIPS 4-40 }\end{array}$ & 0.5400 & $\$ 2.1600$ \\
\hline 5 & 8 & 445-3464-1-ND & $\begin{array}{c}\text { CAP CER 2.2UF 50V Y5V } \\
0805\end{array}$ & 0.1240 & $\$ 0.9920$ \\
\hline 6 & 2 & PCE3915CT-ND & $\begin{array}{c}\text { CAP ALUM 10UF 50V } 20 \% \\
\text { SMD }\end{array}$ & 0.4300 & $\$ 0.8600$ \\
\hline 7 & 2 & $\begin{array}{l}\text { 0603SFF100F/32CT- } \\
\text { ND }\end{array}$ & $\begin{array}{c}\text { FUSE 1.0A 32V FAST SMD } \\
0603\end{array}$ & 0.3160 & $\$ 0.6320$ \\
\hline 8 & 1 & 513-1774-ND & $\begin{array}{l}\text { INDUCTOR/TRANSFORMER } \\
\text { 22.3UH SMD }\end{array}$ & 7.6000 & $\$ 7.6000$ \\
\hline 9 & 2 & IPP147N12N3 G-ND & $\begin{array}{l}\text { MOSFET N-CH 120V 56A } \\
\text { TO220-3 }\end{array}$ & 1.6210 & $\$ 3.2420$ \\
\hline 10 & 2 & P47LLXT-ND & RES .047 OHM 1/4W 1\% 0805 & 0.7000 & $\$ 1.4000$ \\
\hline 11 & 1 & P330KCCT-ND & $\begin{array}{l}\text { RES 330K OHM 1/8W 1\% } \\
0805\end{array}$ & 0.0276 & $\$ 0.0276$ \\
\hline 12 & 1 & P45.3KCCT-ND & $\begin{array}{l}\text { RES 45.3K OHM 1/8W 1\% } \\
0805\end{array}$ & 0.0276 & $\$ 0.0276$ \\
\hline 13 & 1 & P24.0KFCT-ND & $\begin{array}{c}\text { RES 24.0K OHM 1/4W 1\% } \\
\text { 1206 SMD }\end{array}$ & $\$ 0.10$ & $\$ 0.1000$ \\
\hline 14 & 1 & P25.5KFCT-ND & $\begin{array}{c}\text { RES } 25.5 \mathrm{~K} \text { OHM } 1 / 4 \mathrm{~W} 1 \% \\
1206 \mathrm{SMD}\end{array}$ & $\$ 0.10$ & $\$ 0.1000$ \\
\hline 15 & 1 & 445-6943-1-ND & $\begin{array}{c}\text { CAP CER 4700PF 50V 5\%NP0 } \\
0805\end{array}$ & 0.1650 & $\$ 0.1650$ \\
\hline 16 & 1 & P47KACT-ND & $\begin{array}{c}\text { RES 47K OHM 1/8W 5\% } 0805 \\
\text { SMD }\end{array}$ & $\$ 0.02$ & $\$ 0.0162$ \\
\hline 17 & 1 & P6.04KCCT-ND & $\begin{array}{c}\text { RES } 6.04 \mathrm{~K} \text { OHM } 1 / 8 \mathrm{~W} 1 \% \\
0805 \mathrm{SMD}\end{array}$ & $\$ 0.0276$ & $\$ 0.0276$ \\
\hline 18 & 1 & P0.0ACT-ND & $\begin{array}{l}\text { RES } 0.0 \text { OHM } 1 / 8 \mathrm{~W} 0805 \\
\text { SMD }\end{array}$ & $\$ 0.0172$ & $\$ 0.0172$ \\
\hline
\end{tabular}




\begin{tabular}{|c|c|c|c|c|c|}
\hline 19 & 1 & 399-9186-1-ND & $\begin{array}{l}\text { CAP CER 2000PF 25V 5\% } \\
\text { NP0 } 0805\end{array}$ & $\$ 0.50$ & $\$ 0.5000$ \\
\hline 20 & 1 & $\begin{array}{c}\text { MBRS360T3GOSCT- } \\
\text { ND }\end{array}$ & $\begin{array}{c}\text { DIODE SCHOTTKY 60V 4A } \\
\text { SMC }\end{array}$ & $\$ 0.59$ & $\$ 0.5900$ \\
\hline 21 & 1 & 568-6471-1-ND & $\begin{array}{c}\text { DIODE ZENER 5V 250MW } \\
\text { TO236AB }\end{array}$ & $\$ 0.45$ & $\$ 0.4500$ \\
\hline 22 & 7 & 445-1409-1-ND & $\begin{array}{l}\text { CAP CER 47UF 10V Y5V } \\
1210\end{array}$ & $\$ 0.45$ & $\$ 3.1500$ \\
\hline 23 & 1 & 568-7918-1-ND & $\begin{array}{l}\text { DIODE SMALL SIG 100V } \\
\text { 200MA ALF2 }\end{array}$ & $\$ 0.081$ & $\$ 0.0810$ \\
\hline 24 & 2 & 445-8431-ND & $\begin{array}{c}\text { CAP CER 0.1UF 100V } 10 \% \\
\text { RADIAL }\end{array}$ & $\$ 0.333$ & $\$ 0.6660$ \\
\hline 25 & 2 & ---------------- & RES $1.2 \mathrm{~K} 1 \mathrm{~W}$ & $\$ 0.000$ & $\$ 0.0000$ \\
\hline 26 & 1 & |-------------- & Custom PCB & $\$ 20.20$ & $\$ 20.2000$ \\
\hline \multirow[t]{2}{*}{27} & 1 & ----------------- & LT3748 & $\$ 0.00$ & $\$ 0.0000$ \\
\hline & & & & Total & $\$ 47.16$ \\
\hline
\end{tabular}




\begin{tabular}{|c|c|c|c|}
\hline \multicolumn{4}{|c|}{ Bicycle Dynamo Generator Cost } \\
\hline Quantity & Description & $\begin{array}{l}\text { Unit } \\
\text { Price }\end{array}$ & Extended Price \\
\hline 1 & $\begin{array}{l}\text { Tung Lin Dynamo (http://www.amazon.com/Bike-Bicycle- } \\
\text { Dynamo-Generator-12V/dp/B000OBWMGK) }\end{array}$ & $\$ 29.75$ & $\$ 29.75$ \\
\hline 4 & CAP ALUM 4700UF 50V 20\% SNAP & $\$ 2.59$ & $\$ 10.36$ \\
\hline 3 & CAP ALUM 150UF 16V 20\% RADIAL & $\$ 0.44$ & $\$ 1.32$ \\
\hline 3 & CAP ALUM 10UF 16v 20\% RADIAL & $\$ 0.20$ & $\$ 0.60$ \\
\hline 5 & RES 100 OHM 1/2W 5\% CARBON FILM & $\$ 0.10$ & $\$ 0.50$ \\
\hline 5 & RES 866 OHM METAL FILM 1/2W 1\% & $\$ 0.23$ & $\$ 1.15$ \\
\hline 12 & DIODE SWITCH SS 75V 300MA DO35 & $\$ 0.15$ & $\$ 1.82$ \\
\hline \multirow[t]{3}{*}{1} & RadioShack $®$ Matching Printed Circuit Board & $\$ 3.49$ & $\$ 3.49$ \\
\hline & & Total & $\$ 48.99$ \\
\hline & Price to Make One & & \\
\hline 1 & $\begin{array}{l}\text { Tung Lin Dynamo (http://www.amazon.com/Bike-Bicycle- } \\
\text { Dynamo-Generator-12V/dp/B000OBWMGK) }\end{array}$ & $\$ 29.75$ & $\$ 29.75$ \\
\hline 4 & CAP ALUM 4700UF 50V 20\% SNAP & $\$ 2.59$ & $\$ 10.36$ \\
\hline 1 & CAP ALUM 150UF 16V 20\% RADIAL & $\$ 0.44$ & $\$ 0.44$ \\
\hline 1 & CAP ALUM 10UF 16v 20\% RADIAL & $\$ 0.20$ & $\$ 0.20$ \\
\hline 1 & RES 100 OHM 1/2W 5\% CARBON FILM & $\$ 0.10$ & $\$ 0.10$ \\
\hline 1 & RES 866 OHM METAL FILM 1/2W 1\% & $\$ 0.23$ & $\$ 0.23$ \\
\hline 4 & DIODE SWITCH SS 75V 300MA DO35 & $\$ 0.15$ & $\$ 0.61$ \\
\hline 1 & RadioShack® Matching Printed Circuit Board & $\$ 3.49$ & $\$ 3.49$ \\
\hline & & Total & $\$ 45.18$ \\
\hline
\end{tabular}

\begin{tabular}{|c|c|c|c|}
\hline \multicolumn{3}{|c|}{ Solar Panel Cost } \\
\hline \multirow{2}{*}{ Quantity } & Description & $\begin{array}{c}\text { Unit } \\
\text { Price }\end{array}$ & Extended Price \\
\hline & $\begin{array}{c}\text { Instapark® NEW All Black 10W Mono-crystalline Solar } \\
\text { Panel with 12V Solar Charge Controller } \\
\text { (http://www.amazon.com//nstapark\%C2\%AE-Black-Mono- } \\
\text { crystalline-Charge-Controller/dp/B005LR9IOG) }\end{array}$ & $\$ 49.95$ & $\$ 49.95$ \\
\hline 1 & 12V 7Ah Rechargeable Battery & $\$ 16.89$ & $\$ 16.89$ \\
\hline & & & \\
\hline & & Total & $\$ 66.84$ \\
\hline
\end{tabular}




\section{Appendix B: VPH5-0115-R Data Sheet}

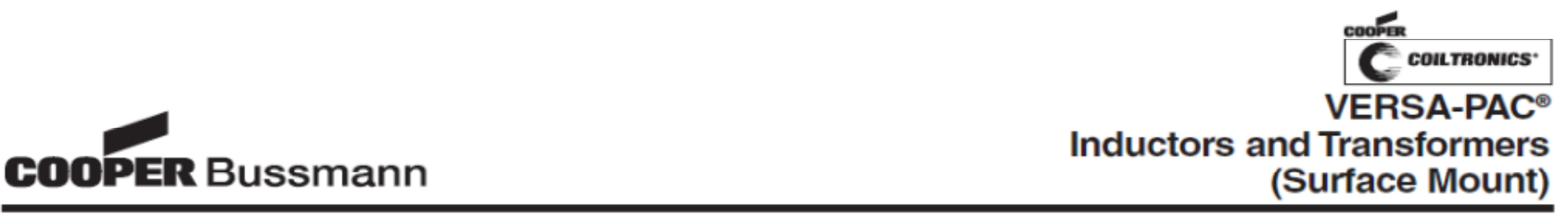

Description

- Six winding, surface mount devices that offer more than $\mathbf{5 0 0}$ usable inductor or transformer configurations

- High power density and low profile

- Low radiated noise and tightly coupled windings

- Power range from 1 Watt - 70 Watts

- Frequency range to over $1 \mathrm{MHz}$

- 500 VAC Isolation

- Ferrite core material

\section{Applications}

- Inductors: buck, boost, coupled, choke, filter, resonant, noise filtering, differential, forward, common mode

- Transformers: flyback, feed forward, push-pull, multiple output, inverter, step-up, step-down, gate drive, base drive, wide band, pulse, control, impedance, isolation, bridging, ringer, converter, auto

Environmental Data

- Storage temperature range: $-55^{\circ} \mathrm{C}$ to $125^{\circ} \mathrm{C}$

- Operating ambient temperature range: $-40^{\circ} \mathrm{C}$ to $+85^{\circ} \mathrm{C}$ (range is application specific). The internal "hot spot" temperature defines the maximum allowable currents, which are limited to $130^{\circ} \mathrm{C}$, including ambient

- Solder reflow temperature: $+260^{\circ} \mathrm{C}$ max for 10 seconds $\max$.

\begin{tabular}{|c|c|c|c|c|c|c|c|c|}
\hline $\begin{array}{l}\text { Part }{ }^{(1)} \\
\text { Number }\end{array}$ & $\begin{array}{c}\text { L(BASE) } \\
\mu \mathrm{H} \\
\text { (NOM) }^{(2)}\end{array}$ & $\begin{array}{l}\text { ISAT(BASE) } \\
\text { Amps } \\
(\text { TYP })^{(2)(4)}\end{array}$ & $\begin{array}{l}\text { IRMS(BASE) } \\
\text { AmpS } \\
(\text { TYP) })^{(3)(5)}\end{array}$ & $\begin{array}{l}\text { R(BASE) } \\
\text { Ohms } \\
\text { (MAX) }\end{array}$ & $\begin{array}{c}\text { Volt- } \mu \text { SEC(BASE) } \\
\mu V S \\
(\text { MAX) })^{(n)}\end{array}$ & $\begin{array}{c}\text { EPEAK(BASE) } \\
\mu J \\
\text { (TYP) }^{(1)}\end{array}$ & $\begin{array}{l}\text { Leakage } \\
\text { Inductance } \\
\text { (BASE) } \mu \mathrm{H} \\
\text { (TYP) }\end{array}$ & $\begin{array}{c}\text { Thermal } \\
\text { Reslstance } \\
{ }^{\circ} \mathrm{C} / \text { Watt } \\
\text { (TYP) }{ }^{(9)}\end{array}$ \\
\hline VPH1-1400-R ${ }^{(10)}$ & $201.6+/-30 \%$ & 0.04 & 0.55 & 0.344 & 32.9 & 0.11 & 0.212 & 60.7 \\
\hline VP1-1400-R & $89.6+1-30 \%$ & 0.06 & 0.85 & 0.145 & 21.8 & 0.11 & 0.096 & 60.7 \\
\hline VPH1-0190-R & $27.4+1-20 \%$ & 0.29 & 0.55 & 0.344 & 32.9 & 0.77 & 0.212 & 60.7 \\
\hline VP1-0190-R & $12.2+/-20 \%$ & 0.43 & 0.85 & 0.145 & 21.8 & 0.77 & 0.096 & 60.7 \\
\hline VPH1-0102-R & $14.7+/-20 \%$ & 0.53 & 0.55 & 0.344 & 32.9 & 1.45 & 0.212 & 60.7 \\
\hline VP1-0102-R & $6.5+1-20 \%$ & 0.80 & 0.85 & 0.145 & 21.8 & 1.45 & 0.096 & 60.7 \\
\hline VPH1-0076-R & $10.9+1-20 \%$ & 0.72 & 0.55 & 0.344 & 32.9 & 1.92 & 0.212 & 60.7 \\
\hline VP1-0076-R & $4.9+1-20 \%$ & 1.06 & 0.85 & 0.145 & 21.8 & 1.92 & 0.096 & 60.7 \\
\hline VPH1-0059-R & $8.5+1-20 \%$ & 0.92 & 0.55 & 0.344 & 32.9 & 2.48 & 0.212 & 60.7 \\
\hline VP1-0059-R & $3.8+1-20 \%$ & 1.37 & 0.85 & 0.145 & 21.8 & 2.48 & 0.096 & 60.7 \\
\hline VPH2-1600-R ${ }^{(10)}$ & $160+/-30 \%$ & 0.07 & 0.95 & 0.159 & 48.3 & 0.29 & 0.165 & 44.0 \\
\hline VP2-1600-R & $78.4+/-30 \%$ & 0.10 & 1.26 & 0.090 & 33.7 & 0.29 & 0.083 & 44.0 \\
\hline VPH2-0216-R & $21.6+/-20 \%$ & 0.53 & 0.95 & 0.159 & 48.3 & 2.11 & 0.165 & 44.0 \\
\hline VP2-0216-R & $10.6+1-20 \%$ & 0.76 & 1.26 & 0.090 & 33.7 & 2.11 & 0.083 & 44.0 \\
\hline VPH2-0116-R & $11.6+/-20 \%$ & 0.99 & 0.95 & 0.159 & 48.3 & 3.94 & 0.165 & 44.0 \\
\hline VP2-0083-R & $4.1+/-20 \%$ & 1.95 & 1.26 & 0.090 & 33.7 & 5.47 & 0.083 & 44.0 \\
\hline VPH2-0066-R & $6.6+1-20 \%$ & 1.74 & 0.95 & 0.159 & 48.3 & 7.01 & 0.165 & 44.0 \\
\hline VP2-0066-R & $3.2+1-20 \%$ & 2.50 & 1.26 & 0.090 & 33.7 & 7.01 & 0.083 & 44.0 \\
\hline VPH3-0780-R ${ }^{(10)}$ & $132+/-30 \%$ & 0.07 & 0.97 & 0.14 & 39.8 & 0.24 & 0.125 & 43.4 \\
\hline VP3-0780-R & $63.2+/-30 \%$ & 0.10 & 1.47 & 0.061 & 27.7 & 0.24 & 0.058 & 43.4 \\
\hline VPH3-0138-R & $23.3+1-20 \%$ & 0.41 & 0.97 & 0.14 & 39.8 & 1.36 & 0.125 & 43.4 \\
\hline VP3-0138-R & $11.2+1-20 \%$ & 0.59 & 1.47 & 0.061 & 27.7 & 1.36 & 0.058 & 43.4 \\
\hline VPH3-0084-R & $14.2+/-20 \%$ & 0.67 & 0.97 & 0.14 & 39.8 & 2.23 & 0.125 & 43.4 \\
\hline VP3-0084-R & $6.8+1-20 \%$ & 0.97 & 1.47 & 0.061 & 27.7 & 2.23 & 0.058 & 43.4 \\
\hline VPH3-0055-R & $9.3+/-20 \%$ & 1.02 & 0.97 & 0.14 & 39.8 & 3.38 & 0.125 & 43.4 \\
\hline VP3-0055-R & $4.5+1-20 \%$ & 1.46 & 1.47 & 0.061 & 27.7 & 3.38 & 0.058 & 43.4 \\
\hline VPH3-0047-R & $7.94+1-20 \%$ & 1.19 & 0.97 & 0.14 & 39.8 & 4.00 & 0.125 & 43.4 \\
\hline VP3-0047-R & $3.8+/-20 \%$ & 1.73 & 1.47 & 0.061 & 27.7 & 4.00 & 0.058 & 43.4 \\
\hline
\end{tabular}

Packaging

- Supplied in tape and reel packaging, 600 (VP01), 300 (VP02), and 200 (VP03) per reel

- Supplied in bulk packaging (VP04 and VP05)

- VP04 \& VP05 tape and reel packaging available. Please contact factory for details. 


\begin{tabular}{|c|c|c|c|c|c|c|c|c|}
\hline $\begin{array}{l}\text { Part }{ }^{(1)} \\
\text { Number }\end{array}$ & $\begin{array}{c}\text { L(BASE) } \\
\underset{\mu H}{(\mathrm{NOM})^{(2)}}\end{array}$ & $\begin{array}{c}\text { ISAT(BASE) } \\
\text { AmpS } \\
\text { (TYP) }^{(3)(4)}\end{array}$ & $\begin{array}{c}\text { IRMS(BASE) } \\
\text { Amps } \\
\text { (TYP) })^{(3)(5)}\end{array}$ & $\begin{array}{l}\text { R(BASE) } \\
\text { Ohms } \\
\left(\text { MAX) }{ }^{(8)}\right.\end{array}$ & $\begin{array}{c}\text { Volt- } \mu \text { SEC(BASE) } \\
\mu V S \\
(\text { MAX) })^{(7)}\end{array}$ & $\begin{array}{c}\text { EPEAK(BASE) } \\
\mu \mathrm{J} \\
\text { (TYP) }^{(8)}\end{array}$ & $\begin{array}{c}\text { Leakage } \\
\text { Inductance } \\
\text { (BASE) } \mu \mathrm{H} \\
\text { (TYP) }\end{array}$ & $\begin{array}{c}\text { Thermal } \\
\text { Reslstance } \\
{ }^{\circ} \text { C/Watt } \\
\text { (TYP) }{ }^{(9)}\end{array}$ \\
\hline VPH4-0860-R ${ }^{(10)}$ & $159.65+/-30 \%$ & 0.11 & 1.41 & 0.0828 & 64.6 & 0.57 & 0.156 & 39.4 \\
\hline VP4-0860-R ${ }^{(10)}$ & $87.0+1-30 \%$ & 0.15 & 1.70 & 0.057 & 44.7 & 0.57 & 0.075 & 39.4 \\
\hline VPH4-0140-R & $23.7+1-20 \%$ & 0.65 & 1.41 & 0.0828 & 64.6 & 3.54 & 0.156 & 39.4 \\
\hline VP4-0140-R & $11.3+/-20 \%$ & 0.95 & 1.70 & 0.057 & 44.7 & 3.54 & 0.075 & 39.4 \\
\hline VPH4-0075-R & $12.7+/-20 \%$ & 1.21 & 1.41 & 0.0828 & 64.6 & 6.55 & 0.156 & 39.4 \\
\hline VP4-0075-R & $6.1+/-20 \%$ & 1.75 & 1.70 & 0.057 & 44.7 & 6.55 & 0.075 & 39.4 \\
\hline VPH4-0060-R & $10.1+/-20 \%$ & 1.52 & 1.41 & 0.0828 & 64.6 & 8.16 & 0.156 & 39.4 \\
\hline VP4-0060-R & $4.9+/-20 \%$ & 2.18 & 1.70 & 0.057 & 44.7 & 8.16 & 0.075 & 39.4 \\
\hline VPH4-0047-R & $7.94+1-20 \%$ & 1.94 & 1.41 & 0.0828 & 64.6 & 10.52 & 0.156 & 39.4 \\
\hline VP4-0047-R & $3.8+1-20 \%$ & 2.81 & 1.70 & 0.057 & 44.7 & 10.52 & 0.075 & 39.4 \\
\hline VPH5-1200-R ${ }^{(10)}$ & $173+/-30 \%$ & 0.14 & 1.70 & 0.0711 & 98.4 & 1.11 & 0.235 & 30.3 \\
\hline VP5-1200-R & $76.8+/-30 \%$ & 0.20 & 2.08 & 0.047 & 65.6 & 1.11 & 0.105 & 30.3 \\
\hline VPH5-0155-R & $22.3+1-20 \%$ & 1.05 & 1.70 & 0.0711 & 98.4 & 8.83 & 0.235 & 30.3 \\
\hline VP5-0155-R & $9.9+1-20 \%$ & 1.60 & 2.08 & 0.047 & 65.6 & 8.83 & 0.105 & 30.3 \\
\hline VPH5-0083-R & $12+/-20 \%$ & 1.96 & 1.70 & 0.0711 & 98.4 & 16.07 & 0.235 & 30.3 \\
\hline VP5-0083-R & $5.3+1-20 \%$ & 2.95 & 2.08 & 0.047 & 65.6 & 16.07 & 0.105 & 30.3 \\
\hline VPH5-0067-R & $9.65+1-20 \%$ & 2.43 & 1.70 & 0.0711 & 98.4 & 19.83 & 0.235 & 30.3 \\
\hline VP5-0067-R & $4.3+1-20 \%$ & 3.63 & 2.08 & 0.047 & 65.6 & 19.83 & 0.105 & 30.3 \\
\hline VPH5-0053-R & $7.63+/-20 \%$ & 3.07 & 1.70 & 0.0711 & 98.4 & 25.10 & 0.235 & 30.3 \\
\hline VP5-0053-R & $3.4+/-20 \%$ & 4.59 & 2.08 & 0.047 & 65.6 & 25.10 & 0.105 & 30.3 \\
\hline
\end{tabular}

(1) The first three digits in the part number signify the size of the package. The next four digits specify the $A_{L}$, or nanoHenries per turn squared.

(2) Lues $=$ Nominal Inductance of a single winding .

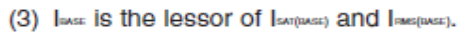

(4) Peak current that will result in $30 \%$ saturation of the core. This current value assumes that equal current flows in all six windings. For applications in which all windings are not simultaneously driven (i.e. flyback, SEPIC, Cuk, etc.), the saturation current per winding may be calculated as follows:

$$
I_{\text {SAT }}=\frac{6 \times I_{\text {SAT(BASE) }}}{\text { Number of Windings Driven }}
$$

(5) RMS Current that results in a surface temperature of approximately $40^{\circ} \mathrm{C}$ above ambient. The $40^{\circ} \mathrm{C}$ rise occurs when the specified current flows through each of the six windings.

(6) Maximum DC Resistance of each winding.

(7) For multiple windings in series, the volt- $\mu$ second ${ }^{\prime \prime o s}(\mu \mathrm{Vs})$ capability varies as the number of windings in series (S):

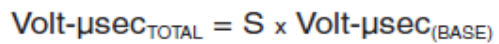

For multiple windings in parallel, the volt- $\mu$ second ${ }_{\text {sow }}(\mu \mathrm{Vs})$ capability is as shown in the table above.
(8) Maximum Energy capability of each winding. This is based on $30 \%$ saturation of the core:

$$
\begin{aligned}
& \text { Energy }_{\text {SERIES }}=\mathrm{S}^{2} \times \frac{1}{2} \times 0.7 \mathrm{~L}_{\mathrm{BASE}} \times \mathrm{I}_{\text {SAT(BASE) }}^{2} \\
& \text { Energy }_{\text {PARALLEL }}=\mathrm{P}^{2} \times \frac{1}{2} \times 0.7 \mathrm{~L}_{\mathrm{BASE}} \times \mathrm{I}_{\text {SAT(BASE) }}^{2}
\end{aligned}
$$

For multiple windings, the energy capability varies as the square of the number of windings. For example, six windings (either parallel or series) can store 36 times more energy than one winding.

(9) Thermal Resistance is the approximate surface temperature rise per Watt of heat loss under still-air conditions. Heat loss is a combination of core loss and wire loss. The number assumes the underlying PCB copper area equals $150 \%$ of the component area.

(10) These devices are designed for feed-forward applications, where load current dominates magnitizing current.
VERSA-PAC temperature rise depends on total power losses and size. Any other PCM configurations other than those suggested could run hotter than acceptable.

Certain topologies or applications must be analyzed for needed requirements and matched with the best VERSA-PAC size and configuration. Proper consideration must be used with all parameters, especially those associated with current rating, energy storage, or maximum volt-seconds.

VERSA-PAC should not be used in off-line or safety related applications. The breakdown voltage from one winding to any other winding is 500 VAC maximum.

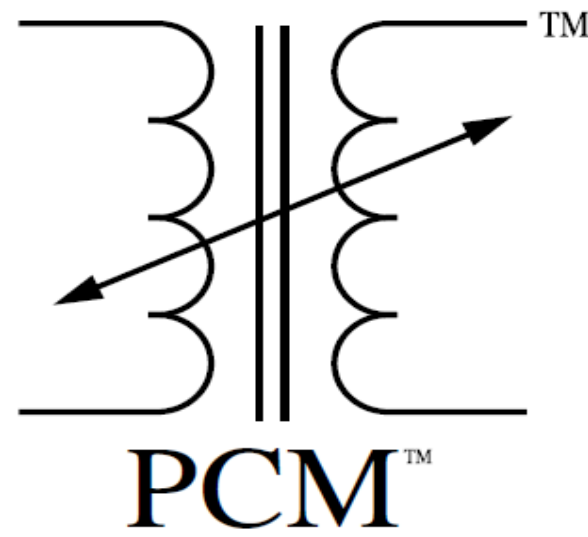

57 I P a g e 


\section{Mechanical Diagrams}

VP5 and VPH5

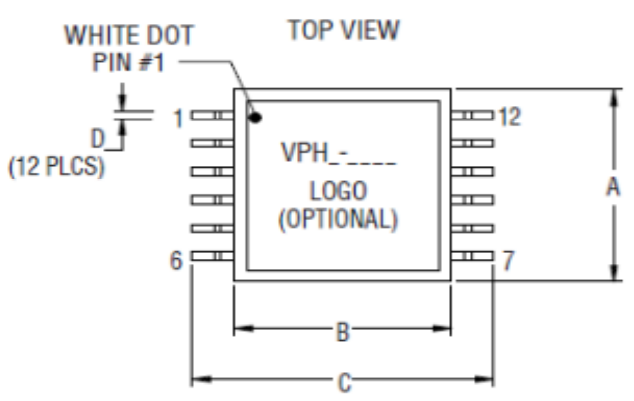

FRONT VIEW

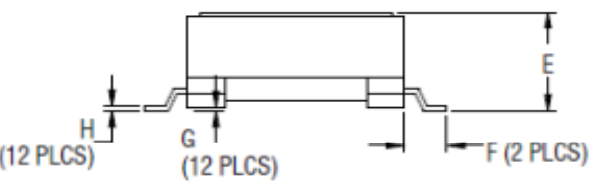

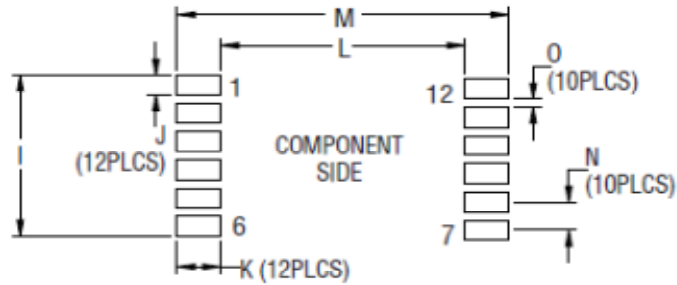

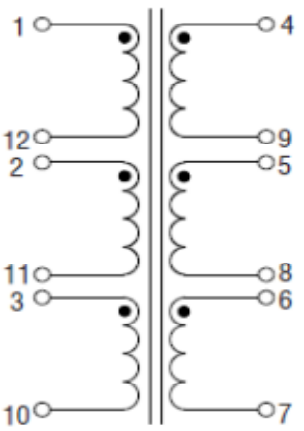

$1: 1: 1: 1: 1: 1$

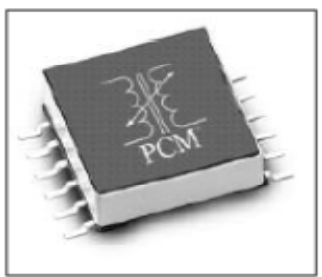

NOTES

1) Tolerances A - I are $\pm 0.25 \mathrm{~mm}$ unless specified otherwise.

2) Tolerances J - P are $+/-0.1 \mathrm{~mm}$ unless specified otherwise.

3) Marking as shown

a) Dot for pin \#1 identification

b) On top of unit: -- VPHx-xxx (product code, size,

4 digit part number per family table.)

c) On top of unit: Versa Pac

Logo (optional)

d) On bottom of unit: wwllyy = (date code) R = (revision evel)

4) All soldering surfaces must be coplanar within $0.102 \mathrm{~mm}$.

\begin{tabular}{|c|c|c|c|c|c|c|c|c|c|c|c|c|c|c|c|}
\hline & $\underset{\max }{\mathbf{A}}$ & $\begin{array}{c}\text { m } \\
\text { ref } \\
\text { ref }\end{array}$ & $\begin{array}{c}\underset{\mathrm{mm}}{\mathrm{C}} \\
\max \end{array}$ & $\underset{\text { ref }}{\mathrm{m}}$ & $\begin{array}{c}\underset{\mathrm{mm}}{\mathrm{E}} \\
\max \end{array}$ & $\underset{\text { ref }}{\mathrm{mm}}$ & $\begin{array}{c}\mathbf{G} \\
\mathrm{mm} \\
\text { ref }\end{array}$ & $\underset{\mathrm{mm}}{\mathrm{m}}$ & $\underset{\text { ref }}{1}$ & $\underset{\mathbf{m m}}{\mathrm{J}}$ & $\underset{\mathbf{m m}}{\mathbf{K}}$ & $\underset{\text { ref }}{\mathrm{mm}}$ & $\underset{\mathrm{mm}}{\mathrm{M}}$ & $\underset{\mathrm{mm}}{\mathrm{N}}$ & $\begin{array}{c}\mathrm{O} \\
\mathrm{mm}\end{array}$ \\
\hline /P5 and VPH5 & 21.0 & 21.0 & 28.5 & 0.7 & 10.8 & 2.95 & 0.1 & 0.4 & 17.25 & 2.25 & 3.15 & 22.7 & 29.0 & 3.0 & 0.75 \\
\hline
\end{tabular}

Inductance Characteristics

OCL vs. Isat

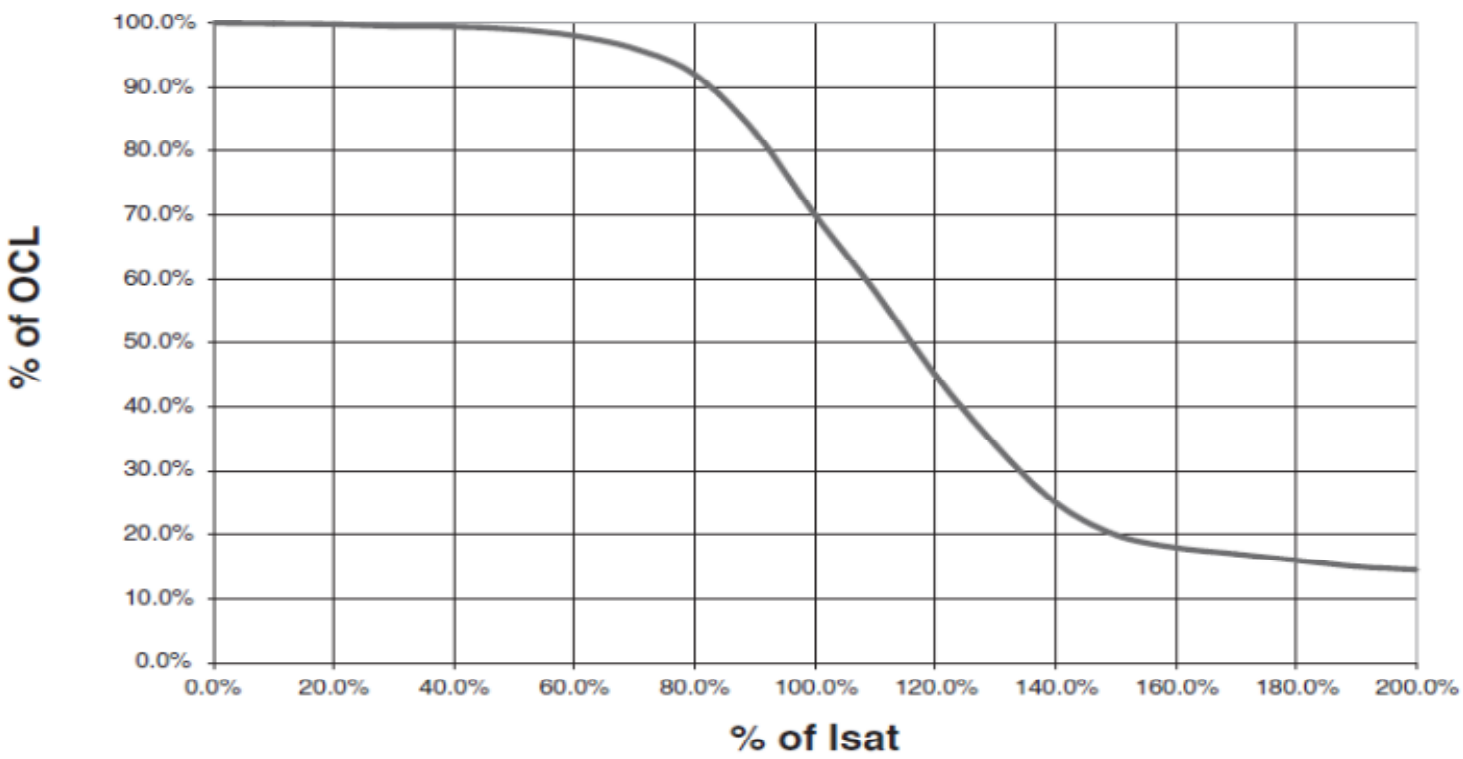




\section{Appendix C: Bicycle Dynamo Generator}

\section{Tung Lin Dynamo}

\begin{tabular}{|c|c|c|}
\hline \multicolumn{3}{|c|}{ Tung Lin Dynamo 12V 6W (Unloaded, High Terminal) } \\
\hline \multicolumn{2}{|c|}{$\begin{array}{c}\text { Buy From: http://www.amazon.com/Bike-Bicycle-Dynamo-Generator- } \\
\text { 12V/dp/B000OBWMGK/ref=cm_cr_pr_product_top }\end{array}$} \\
\hline Speed (m/h) & Vout (VAC) & I (A) \\
\hline 9 & 16 & 1.1 \\
\hline 11 & 19.85 & 1.2 \\
\hline 15 & 24.85 & 1.3 \\
\hline 19 & 30.5 & 1.34 \\
\hline
\end{tabular}

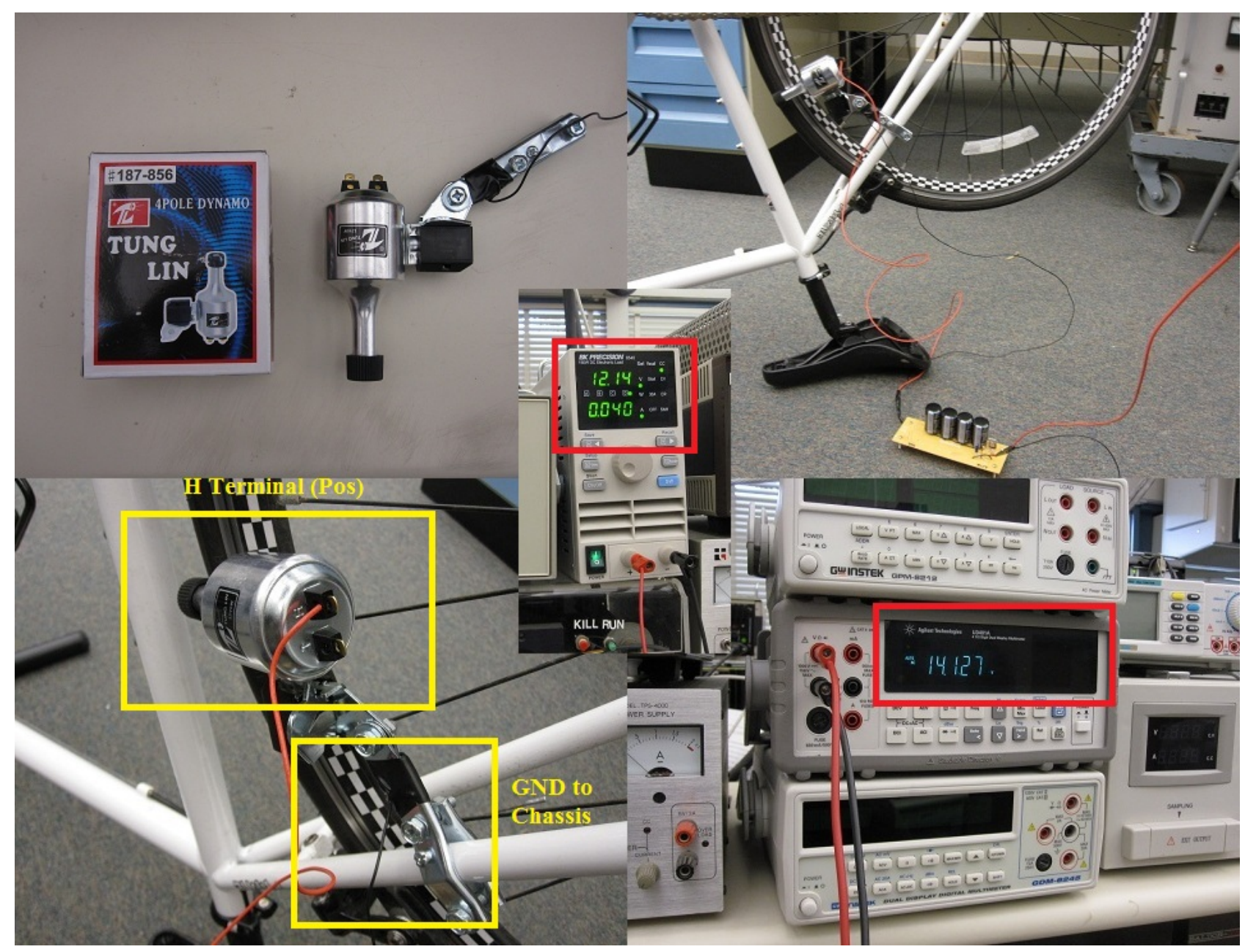




\section{Simulation}
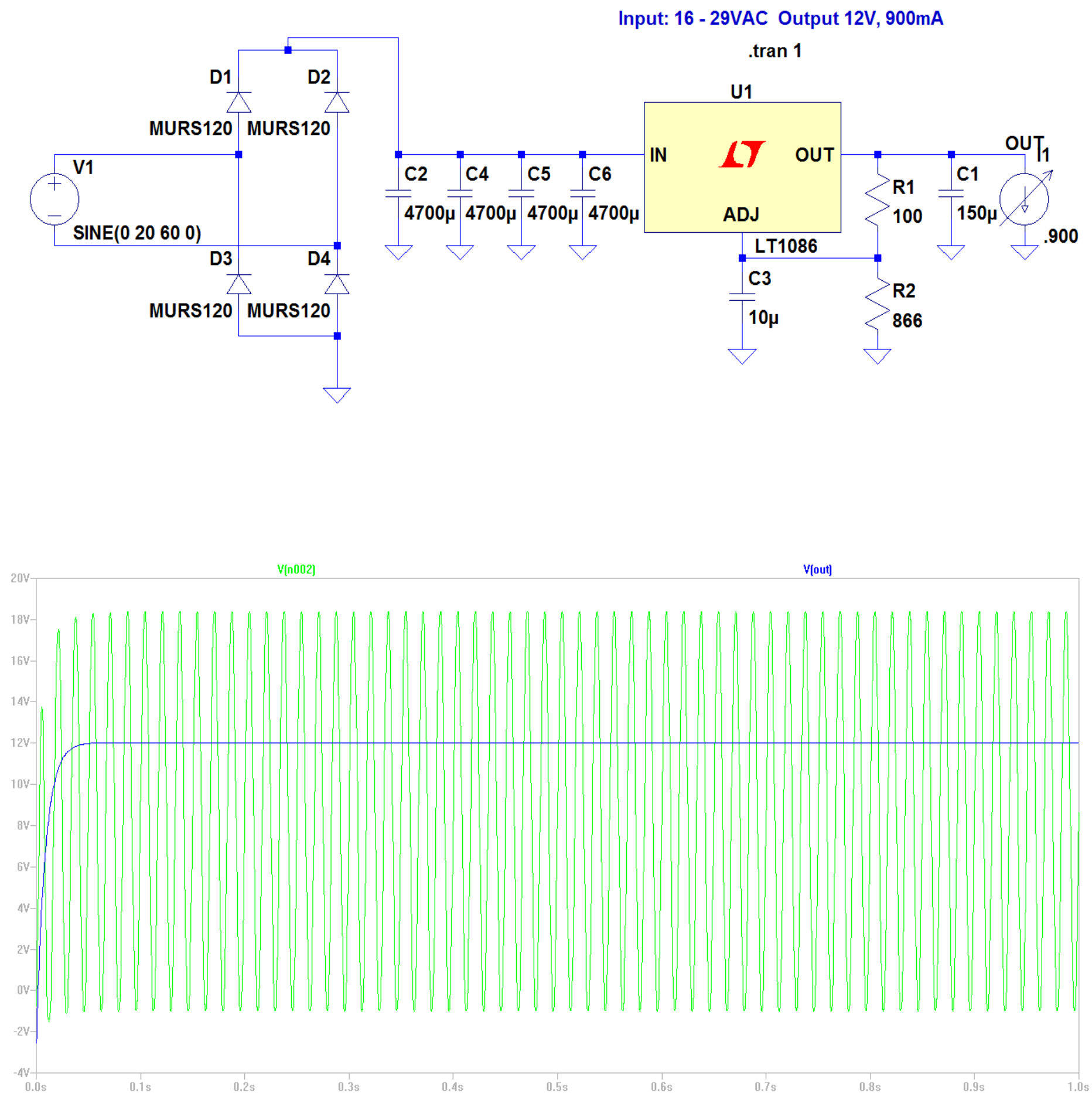


\section{Portable Stationary Bike Converter Design}
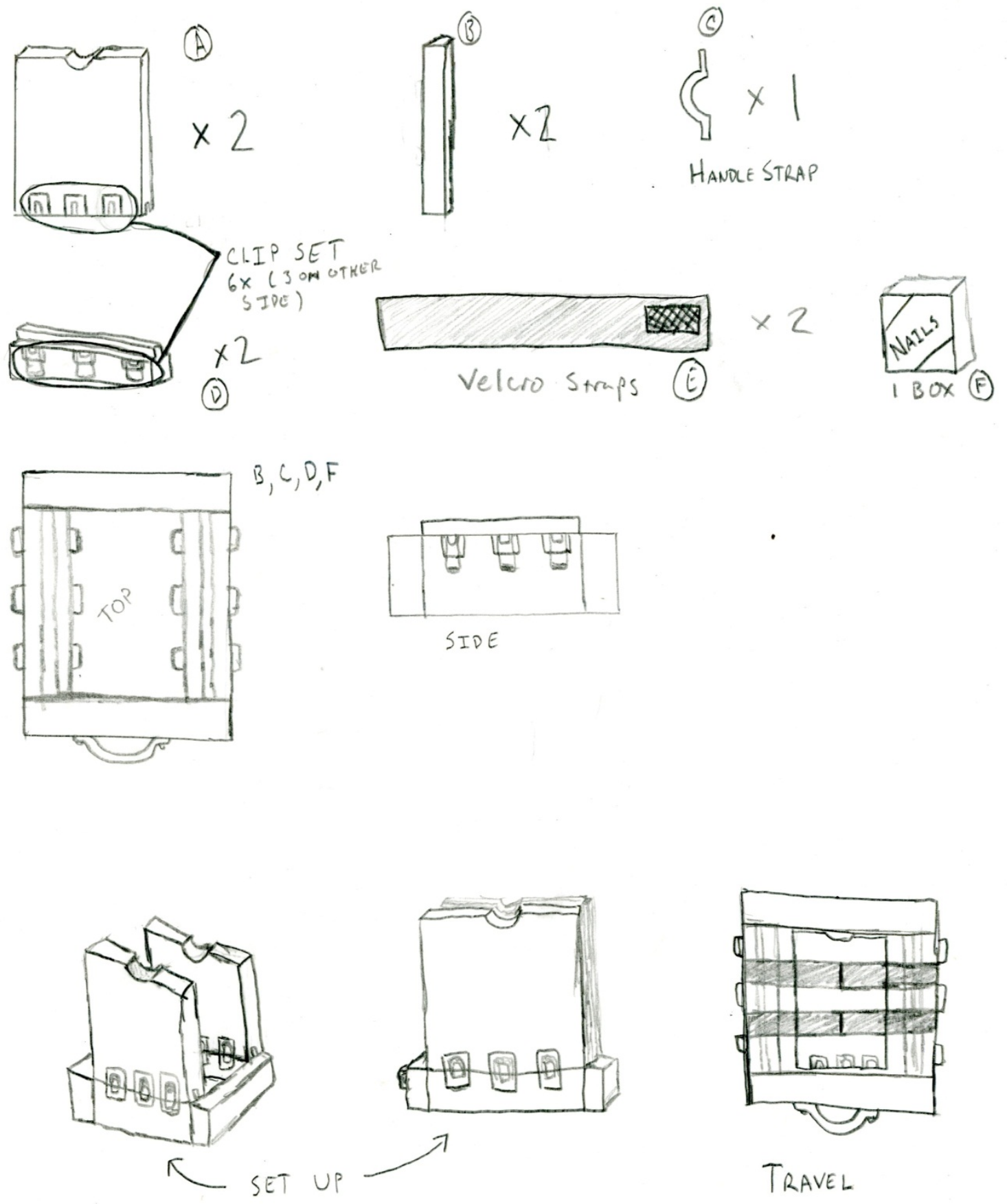


\section{Appendix D: Solar Panel}

\section{SS1203 solar controller instruction Please read carefully before using}

\section{Introduction}

SS1203 solar controller is designed for small solar energy generation system. It takes the industrial-level microchip, integrated senser and non-touch control technology, with perfect over charge/discharge; converse connection and lightning strike protections. It is the high effect, energy saving, safety and sever environment tolerance advantage, that prolong the battery life cycle and keep the load working well. Its cheap cost and high stability can meet the need of the small solar PV energy generation system requirement.

\section{Technical data}

\begin{tabular}{|c|c|c|c|}
\hline \multicolumn{2}{|c|}{ Type } & & SS 1203 \\
\hline \multicolumn{2}{|c|}{ Rated voltage (VDC) } & & 12 \\
\hline \multicolumn{2}{|c|}{ Rated load current (A) } & & 3 \\
\hline \multicolumn{2}{|c|}{ Max. PV watts (Wp) } & & 36 \\
\hline \multirow{2}{*}{$\begin{array}{l}\text { Over charge } \\
\text { (V) }\end{array}$} & Protection & & $14.4 \pm 0.1$ \\
\hline & Resume & & $13.3 \pm 0.1$ \\
\hline \multirow{2}{*}{$\begin{array}{c}\text { Over } \\
\text { discharge } \\
\text { (V) }\end{array}$} & Protection & & $11.1 \pm 0.1$ \\
\hline & Resume & & $13.2 \pm 0.1$ \\
\hline \multirow{2}{*}{$\begin{array}{l}\text { Load } \\
\text { Over voltage } \\
\text { (V) }\end{array}$} & Protection & & $16.5 \pm 0.1$ \\
\hline & Resume & & $15.0 \pm 0.1$ \\
\hline \multicolumn{2}{|c|}{ Ambient temperature } & & $\begin{array}{c}-25^{\circ} \mathrm{C} \sim 50^{\circ} \mathrm{C} \\
\text { Industrial standard microchip }\end{array}$ \\
\hline \multicolumn{2}{|c|}{ altitude $(\mathrm{m})$} & & $\leqslant 4500$ meter \\
\hline \multicolumn{2}{|c|}{$\begin{array}{l}\text { Battery converse connection } \\
\text { protection }\end{array}$} & Batter & $\begin{array}{l}\text { "+" " -" polarity converse connection. } \\
\text { If the fuse broken, change it. }\end{array}$ \\
\hline \multicolumn{2}{|c|}{$\begin{array}{l}\text { Solar panel converse } \\
\text { Connection protection }\end{array}$} & $\begin{array}{l}\text { If the solar panel } \\
\text { the polarity. }\end{array}$ & “+” “-” polarity converse connection, correct \\
\hline \multicolumn{2}{|c|}{$\begin{array}{l}\text { Over current and short circuit } \\
\text { protection }\end{array}$} & $\begin{array}{l}\text { The load curren } \\
\text { broken, change }\end{array}$ & $\begin{array}{l}\text { tis more than max, discharge current and the fuse } \\
\text { the fuse. }\end{array}$ \\
\hline \multicolumn{2}{|c|}{ Battery open-circuit protection } & $\begin{array}{l}\text { When the solar } \\
\text { controller will }\end{array}$ & $\begin{array}{l}\text { Ir panel is running and the battery is open-circuit, } \\
\text { l restrict the load voltage to protect it. }\end{array}$ \\
\hline
\end{tabular}


III Installation and usage

Please connect the controller according the drawing below. Firstly, connect the battery, then connect the solar panel, at last connect the load. The disassembly sequence is contrary to installation.

\section{Solar panels}

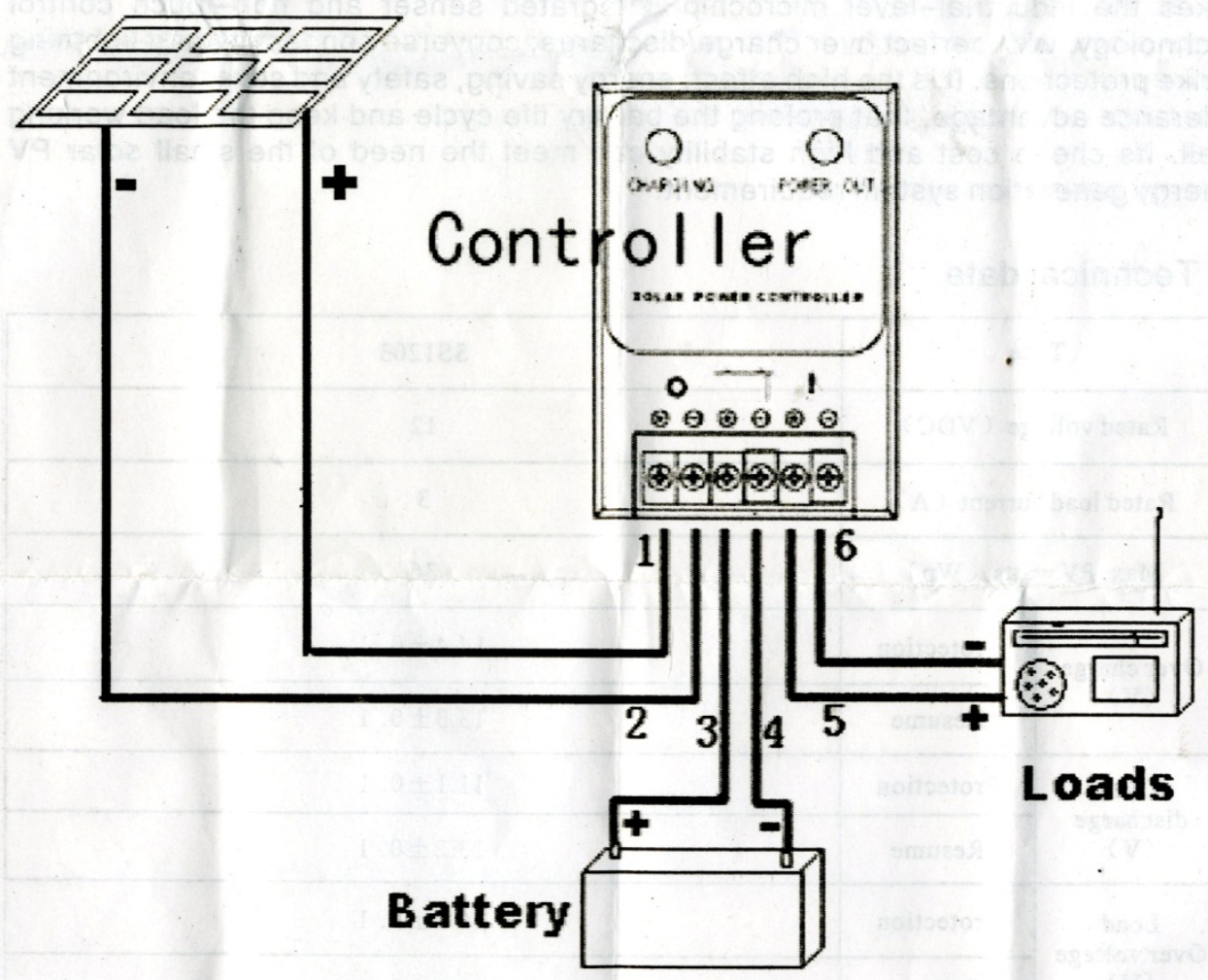

\section{Notes}

1. Don't connect any AVR (automatic voltage regulation) or charger with the end of the solar panel

2、Don't connect the battery with the end of the solar panel directly

N Trouble elimination

\begin{tabular}{|c|c|}
\hline Trouble & Method \\
\hline No indication, no output & To check the fuse \\
\hline Charge indicator flicker & The battery is not connected well. \\
\hline
\end{tabular}

